\title{
Basel Committee on Banking Supervision
}

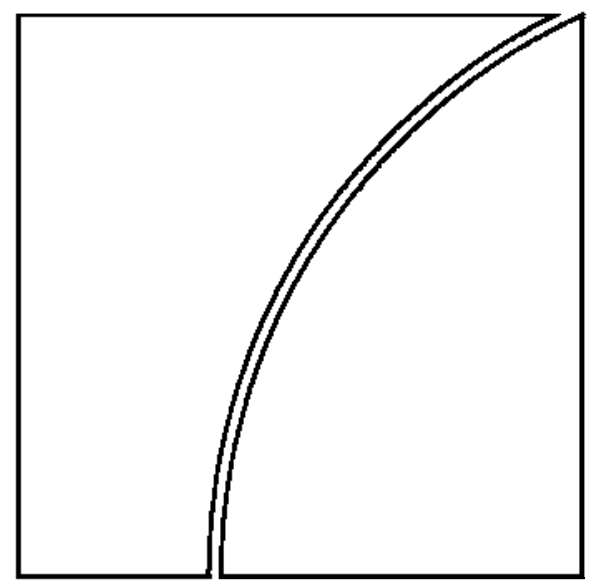

\section{Basel III: A global regulatory framework for more resilient banks and banking systems}

December 2010 (rev June 2011) 

Copies of publications are available from:

Bank for International Settlements

Communications

$\mathrm{CH}-4002$ Basel, Switzerland

E-mail: publications@bis.org

Fax: +41612809100 and +41612808100

(C) Bank for International Settlements 2010. All rights reserved. Brief excerpts may be reproduced or translated provided the source is stated.

ISBN print: 92-9131-859-0

ISBN web: 92-9197-859-0 



\section{Contents}

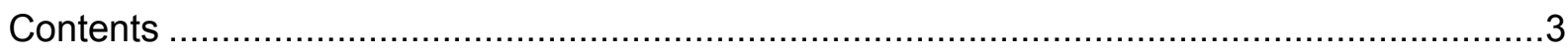

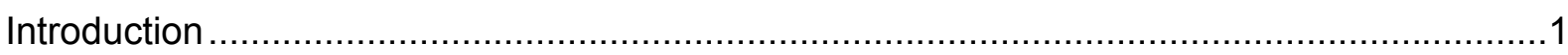

A. Strengthening the global capital framework ......................................................

1. Raising the quality, consistency and transparency of the capital base .................2

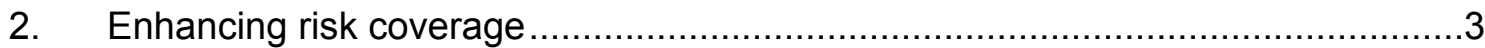

3. Supplementing the risk-based capital requirement with a leverage ratio ...............4

4. Reducing procyclicality and promoting countercyclical buffers ............................5

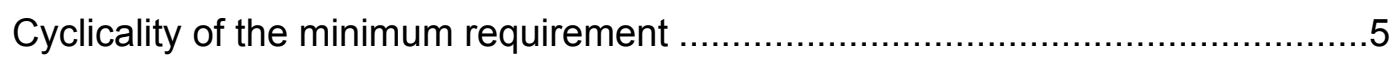

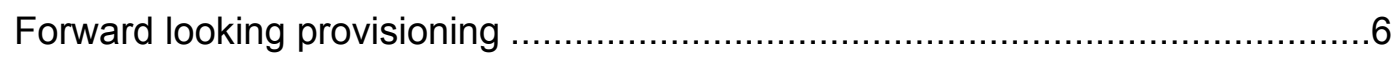

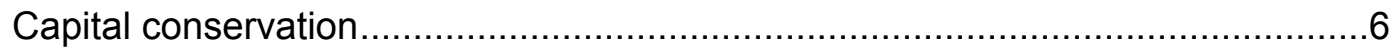

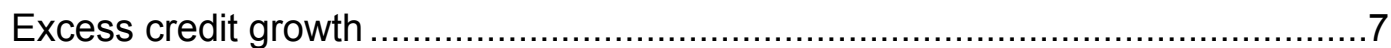

5. Addressing systemic risk and interconnectedness ......................................

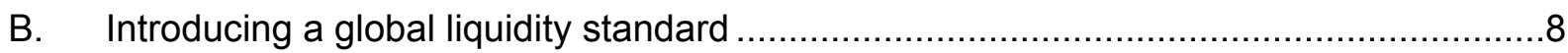

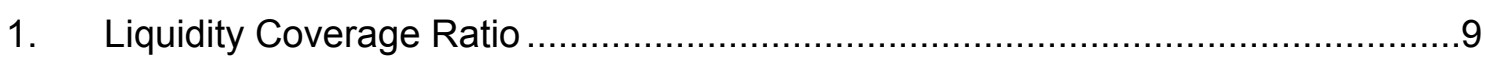

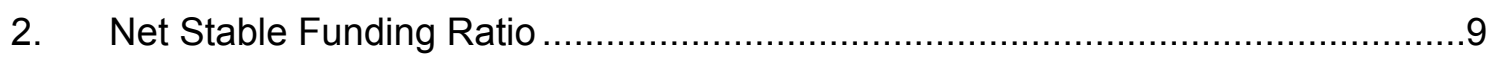

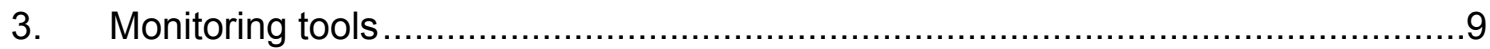

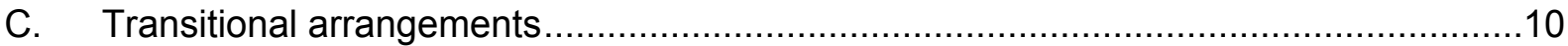

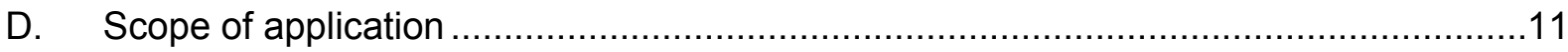

Part 1: Minimum capital requirements and buffers …..................................................12

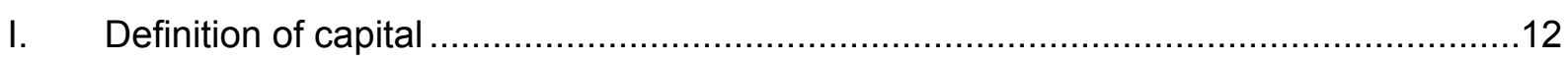

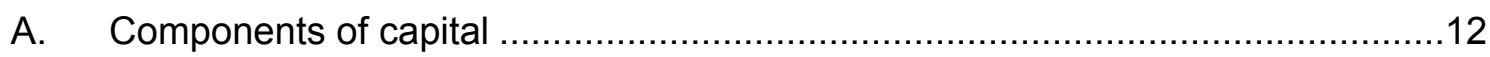

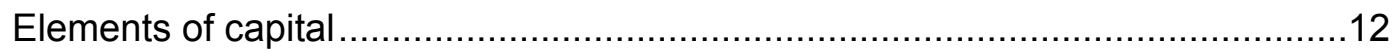

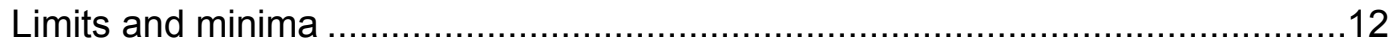

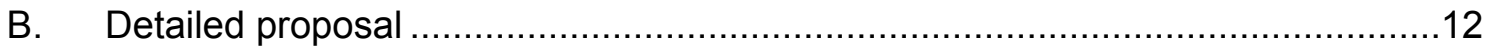

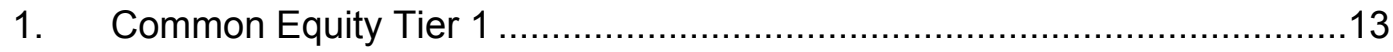

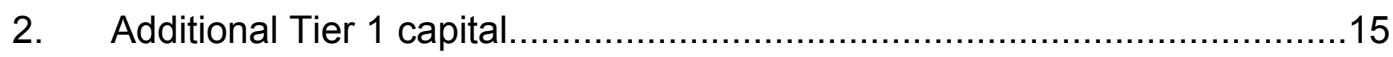

3. Tier 2 capital ........................................................................... 17

4. Minority interest (ie non-controlling interest) and other capital issued out of consolidated subsidiaries that is held by third parties ..............................19

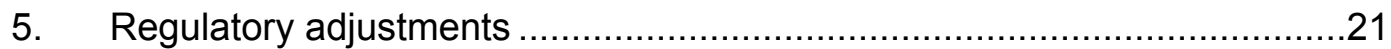

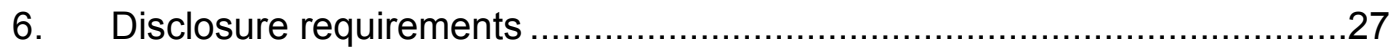

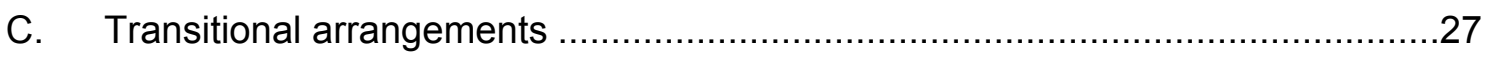

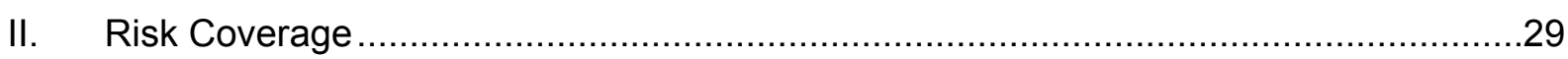

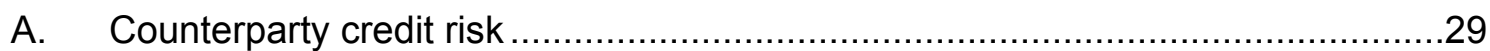

1. Revised metric to better address counterparty credit risk, credit valuation adjustments and wrong-way risk. 
2. Asset value correlation multiplier for large financial institutions ................. 39

3. Collateralised counterparties and margin period of risk .......................... 40

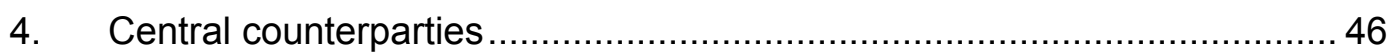

5. Enhanced counterparty credit risk management requirements................. 46

B. Addressing reliance on external credit ratings and minimising cliff effects..........51

1. Standardised inferred rating treatment for long-term exposures............... 51

2. Incentive to avoid getting exposures rated......................................... 52

3. Incorporation of IOSCO's Code of Conduct Fundamentals for Credit Rating

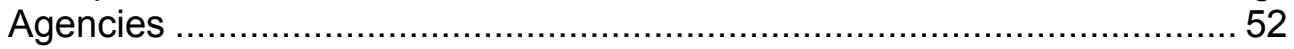

4. "Cliff effects" arising from guarantees and credit derivatives - Credit risk

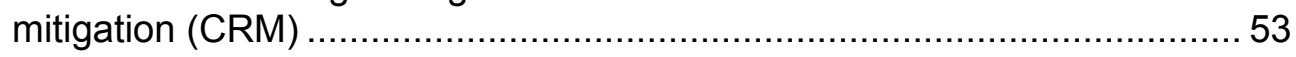

5. Unsolicited ratings and recognition of ECAls .................................... 54

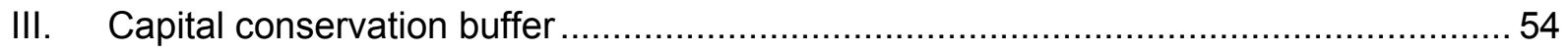

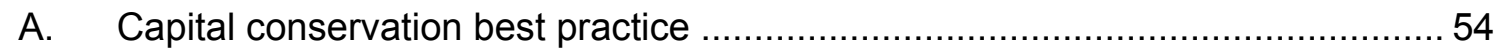

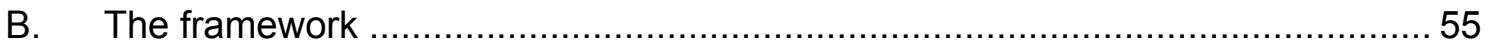

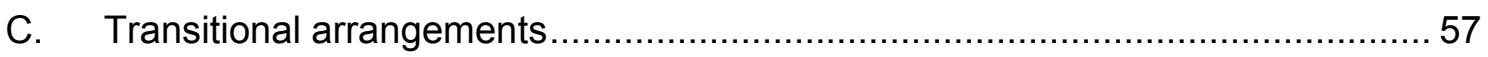

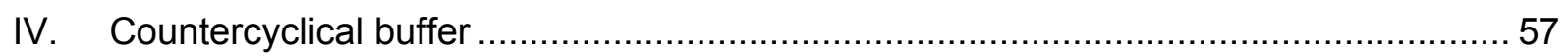

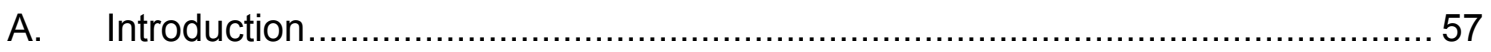

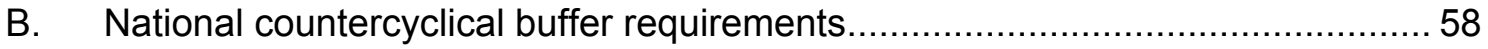

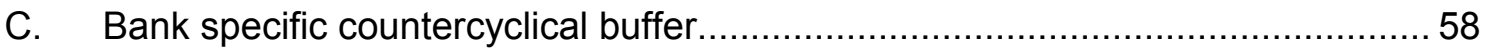

D. Extension of the capital conservation buffer.................................................... 59

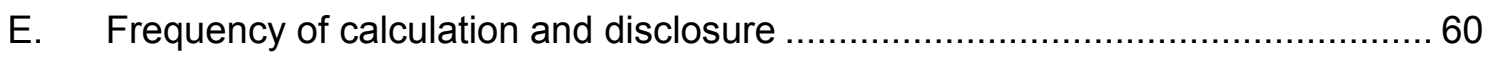

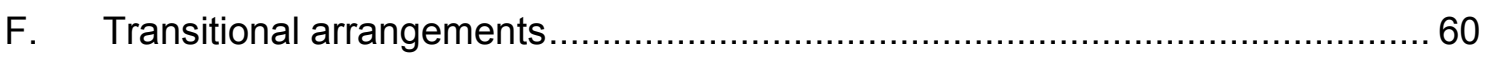

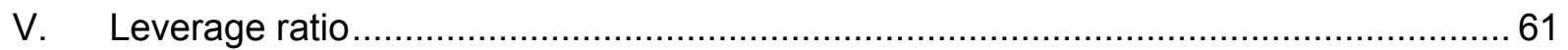

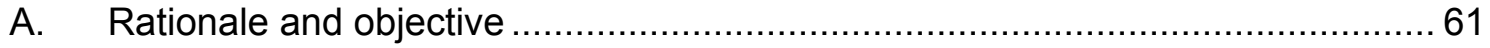

B. Definition and calculation of the leverage ratio............................................... 61

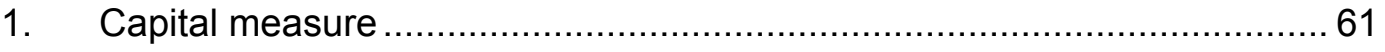

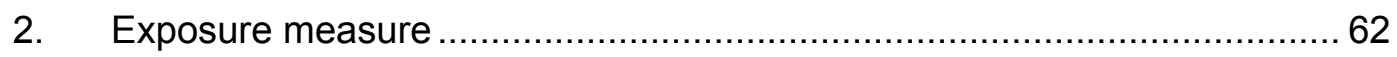

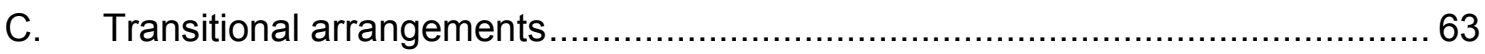

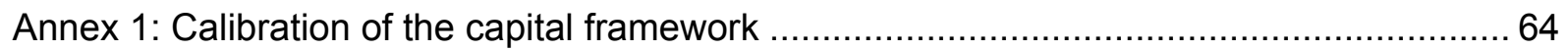

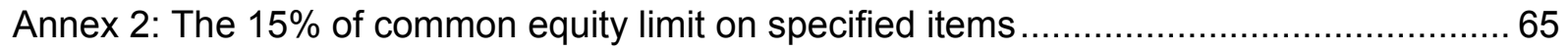

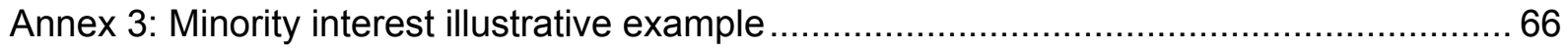

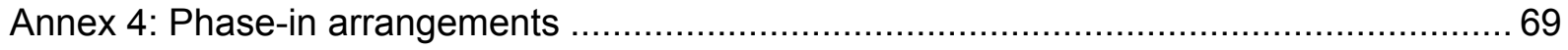




\section{Abbreviations}

\begin{tabular}{|c|c|}
\hline $\mathrm{ABCP}$ & Asset-backed commercial paper \\
\hline ASF & Available Stable Funding \\
\hline AVC & Asset value correlation \\
\hline $\mathrm{CCF}$ & Credit conversion factor \\
\hline CCPs & Central counterparties \\
\hline CCR & Counterparty credit risk \\
\hline CD & Certificate of Deposit \\
\hline CDS & Credit default swap \\
\hline $\mathrm{CP}$ & Commercial Paper \\
\hline CRM & Credit risk mitigation \\
\hline CUSIP & Committee on Uniform Security Identification Procedures \\
\hline CVA & Credit valuation adjustment \\
\hline DTAs & Deferred tax assets \\
\hline DTLs & Deferred tax liabilities \\
\hline DVA & Debit valuation adjustment \\
\hline DvP & Delivery-versus-payment \\
\hline EAD & Exposure at default \\
\hline ECAI & External credit assessment institution \\
\hline EL & Expected Loss \\
\hline EPE & Expected positive exposure \\
\hline FIRB & Foundation internal ratings-based approach \\
\hline IMM & Internal model method \\
\hline IRB & Internal ratings-based \\
\hline IRC & Incremental risk charge \\
\hline ISIN & International Securities Identification Number \\
\hline LCR & Liquidity Coverage Ratio \\
\hline LGD & Loss given default \\
\hline MtM & Mark-to-market \\
\hline NSFR & Net Stable Funding Ratio \\
\hline OBS & Off-balance sheet \\
\hline PD & Probability of default \\
\hline PSE & Public sector entity \\
\hline PvP & Payment-versus-payment \\
\hline RBA & Ratings-based approach \\
\hline RSF & Required Stable Funding \\
\hline
\end{tabular}


Securities financing transaction

SIV

Structured investment vehicle

SME

Small and medium-sized Enterprise

SPV

Special purpose vehicle

VaR

Value-at-risk

VRDN

Variable Rate Demand Note 


\section{Introduction}

1. This document, together with the document Basel III: International framework for liquidity risk measurement, standards and monitoring, presents the Basel Committee's ${ }^{1}$ reforms to strengthen global capital and liquidity rules with the goal of promoting a more resilient banking sector. The objective of the reforms is to improve the banking sector's ability to absorb shocks arising from financial and economic stress, whatever the source, thus reducing the risk of spillover from the financial sector to the real economy. This document sets out the rules text and timelines to implement the Basel III framework.

2. The Committee's comprehensive reform package addresses the lessons of the financial crisis. Through its reform package, the Committee also aims to improve risk management and governance as well as strengthen banks' transparency and disclosures. ${ }^{2}$ Moreover, the reform package includes the Committee's efforts to strengthen the resolution of systemically significant cross-border banks. ${ }^{3}$

3. A strong and resilient banking system is the foundation for sustainable economic growth, as banks are at the centre of the credit intermediation process between savers and investors. Moreover, banks provide critical services to consumers, small and medium-sized enterprises, large corporate firms and governments who rely on them to conduct their daily business, both at a domestic and international level.

4. One of the main reasons the economic and financial crisis, which began in 2007, became so severe was that the banking sectors of many countries had built up excessive onand off-balance sheet leverage. This was accompanied by a gradual erosion of the level and quality of the capital base. At the same time, many banks were holding insufficient liquidity buffers. The banking system therefore was not able to absorb the resulting systemic trading and credit losses nor could it cope with the reintermediation of large off-balance sheet exposures that had built up in the shadow banking system. The crisis was further amplified by a procyclical deleveraging process and by the interconnectedness of systemic institutions through an array of complex transactions. During the most severe episode of the crisis, the market lost confidence in the solvency and liquidity of many banking institutions. The weaknesses in the banking sector were rapidly transmitted to the rest of the financial system and the real economy, resulting in a massive contraction of liquidity and credit availability. Ultimately the public sector had to step in with unprecedented injections of liquidity, capital support and guarantees, exposing taxpayers to large losses.

1 The Basel Committee on Banking Supervision consists of senior representatives of bank supervisory authorities and central banks from Argentina, Australia, Belgium, Brazil, Canada, China, France, Germany, Hong Kong SAR, India, Indonesia, Italy, Japan, Korea, Luxembourg, Mexico, the Netherlands, Russia, Saudi Arabia, Singapore, South Africa, Spain, Sweden, Switzerland, Turkey, the United Kingdom and the United States. It usually meets at the Bank for International Settlements (BIS) in Basel, Switzerland, where its permanent Secretariat is located.

2 In July 2009, the Committee introduced a package of measures to strengthen the 1996 rules governing trading book capital and to enhance the three pillars of the Basel II framework. See Enhancements to the Basel II framework (July 2009), available at www.bis.org/publ/bcbs157.htm.

3 These efforts include the Basel Committee's recommendations to strengthen national resolution powers and their cross-border implementation. The Basel Committee mandated its Cross-border Bank Resolution Group to report on the lessons from the crisis, on recent changes and adaptations of national frameworks for crossborder resolutions, the most effective elements of current national frameworks and those features of current national frameworks that may hamper optimal responses to crises. See Report and recommendations of the Cross-border Bank Resolution Group (March 2010), available at www.bis.org/publ/bcbs169.htm. 
5. The effect on banks, financial systems and economies at the epicentre of the crisis was immediate. However, the crisis also spread to a wider circle of countries around the globe. For these countries the transmission channels were less direct, resulting from a severe contraction in global liquidity, cross-border credit availability and demand for exports. Given the scope and speed with which the recent and previous crises have been transmitted around the globe as well as the unpredictable nature of future crises, it is critical that all countries raise the resilience of their banking sectors to both internal and external shocks.

6. To address the market failures revealed by the crisis, the Committee is introducing a number of fundamental reforms to the international regulatory framework. The reforms strengthen bank-level, or microprudential, regulation, which will help raise the resilience of individual banking institutions to periods of stress. The reforms also have a macroprudential focus, addressing system-wide risks that can build up across the banking sector as well as the procyclical amplification of these risks over time. Clearly these micro and macroprudential approaches to supervision are interrelated, as greater resilience at the individual bank level reduces the risk of system-wide shocks.

\section{A. Strengthening the global capital framework}

7. The Basel Committee is raising the resilience of the banking sector by strengthening the regulatory capital framework, building on the three pillars of the Basel II framework. The reforms raise both the quality and quantity of the regulatory capital base and enhance the risk coverage of the capital framework. They are underpinned by a leverage ratio that serves as a backstop to the risk-based capital measures, is intended to constrain excess leverage in the banking system and provide an extra layer of protection against model risk and measurement error. Finally, the Committee is introducing a number of macroprudential elements into the capital framework to help contain systemic risks arising from procyclicality and from the interconnectedness of financial institutions.

\section{Raising the quality, consistency and transparency of the capital base}

8. It is critical that banks' risk exposures are backed by a high quality capital base. The crisis demonstrated that credit losses and writedowns come out of retained earnings, which is part of banks' tangible common equity base. It also revealed the inconsistency in the definition of capital across jurisdictions and the lack of disclosure that would have enabled the market to fully assess and compare the quality of capital between institutions.

9. To this end, the predominant form of Tier 1 capital must be common shares and retained earnings. This standard is reinforced through a set of principles that also can be tailored to the context of non-joint stock companies to ensure they hold comparable levels of high quality Tier 1 capital. Deductions from capital and prudential filters have been harmonised internationally and generally applied at the level of common equity or its equivalent in the case of non-joint stock companies. The remainder of the Tier 1 capital base must be comprised of instruments that are subordinated, have fully discretionary noncumulative dividends or coupons and have neither a maturity date nor an incentive to redeem. Innovative hybrid capital instruments with an incentive to redeem through features such as step-up clauses, currently limited to $15 \%$ of the Tier 1 capital base, will be phased out. In addition, Tier 2 capital instruments will be harmonised and so-called Tier 3 capital instruments, which were only available to cover market risks, eliminated. Finally, to improve market discipline, the transparency of the capital base will be improved, with all elements of capital required to be disclosed along with a detailed reconciliation to the reported accounts. 
10. The Committee is introducing these changes in a manner that minimises the disruption to capital instruments that are currently outstanding. It also continues to review the role that contingent capital should play in the regulatory capital framework.

\section{Enhancing risk coverage}

11. One of the key lessons of the crisis has been the need to strengthen the risk coverage of the capital framework. Failure to capture major on- and off-balance sheet risks, as well as derivative related exposures, was a key destabilising factor during the crisis.

12. In response to these shortcomings, the Committee in July 2009 completed a number of critical reforms to the Basel II framework. These reforms will raise capital requirements for the trading book and complex securitisation exposures, a major source of losses for many internationally active banks. The enhanced treatment introduces a stressed value-at-risk $(\mathrm{VaR})$ capital requirement based on a continuous 12-month period of significant financial stress. In addition, the Committee has introduced higher capital requirements for so-called resecuritisations in both the banking and the trading book. The reforms also raise the standards of the Pillar 2 supervisory review process and strengthen Pillar 3 disclosures. The Pillar 1 and Pillar 3 enhancements must be implemented by the end of 2011; the Pillar 2 standards became effective when they were introduced in July 2009. The Committee is also conducting a fundamental review of the trading book. The work on the fundamental review of the trading book is targeted for completion by year-end 2011.

13. This document also introduces measures to strengthen the capital requirements for counterparty credit exposures arising from banks' derivatives, repo and securities financing activities. These reforms will raise the capital buffers backing these exposures, reduce procyclicality and provide additional incentives to move OTC derivative contracts to central counterparties, thus helping reduce systemic risk across the financial system. They also provide incentives to strengthen the risk management of counterparty credit exposures.

14. To this end, the Committee is introducing the following reforms:

(a) Going forward, banks must determine their capital requirement for counterparty credit risk using stressed inputs. This will address concerns about capital charges becoming too low during periods of compressed market volatility and help address procyclicality. The approach, which is similar to what has been introduced for market risk, will also promote more integrated management of market and counterparty credit risk.

(b) Banks will be subject to a capital charge for potential mark-to-market losses (ie credit valuation adjustment - CVA - risk) associated with a deterioration in the credit worthiness of a counterparty. While the Basel II standard covers the risk of a counterparty default, it does not address such CVA risk, which during the financial crisis was a greater source of losses than those arising from outright defaults.

(c) The Committee is strengthening standards for collateral management and initial margining. Banks with large and illiquid derivative exposures to a counterparty will have to apply longer margining periods as a basis for determining the regulatory capital requirement. Additional standards have been adopted to strengthen collateral risk management practices.

(d) To address the systemic risk arising from the interconnectedness of banks and other financial institutions through the derivatives markets, the Committee is supporting the efforts of the Committee on Payments and Settlement Systems (CPSS) and the 
International Organization of Securities Commissions (IOSCO) to establish strong standards for financial market infrastructures, including central counterparties. The capitalisation of bank exposures to central counterparties (CCPs) will be based in part on the compliance of the CCP with such standards, and will be finalised after a consultative process in 2011. A bank's collateral and mark-to-market exposures to CCPs meeting these enhanced principles will be subject to a low risk weight, proposed at 2\%; and default fund exposures to CCPs will be subject to risk-sensitive capital requirements. These criteria, together with strengthened capital requirements for bilateral OTC derivative exposures, will create strong incentives for banks to move exposures to such CCPs. Moreover, to address systemic risk within the financial sector, the Committee also is raising the risk weights on exposures to financial institutions relative to the non-financial corporate sector, as financial exposures are more highly correlated than non-financial ones.

(e) The Committee is raising counterparty credit risk management standards in a number of areas, including for the treatment of so-called wrong-way risk, ie cases where the exposure increases when the credit quality of the counterparty deteriorates. It also issued final additional guidance for the sound backtesting of counterparty credit exposures.

15. Finally, the Committee assessed a number of measures to mitigate the reliance on external ratings of the Basel II framework. The measures include requirements for banks to perform their own internal assessments of externally rated securitisation exposures, the elimination of certain "cliff effects" associated with credit risk mitigation practices, and the incorporation of key elements of the IOSCO Code of Conduct Fundamentals for Credit Rating Agencies into the Committee's eligibility criteria for the use of external ratings in the capital framework. The Committee also is conducting a more fundamental review of the securitisation framework, including its reliance on external ratings.

\section{Supplementing the risk-based capital requirement with a leverage ratio}

16. One of the underlying features of the crisis was the build up of excessive on- and off-balance sheet leverage in the banking system. The build up of leverage also has been a feature of previous financial crises, for example leading up to September 1998. During the most severe part of the crisis, the banking sector was forced by the market to reduce its leverage in a manner that amplified downward pressure on asset prices, further exacerbating the positive feedback loop between losses, declines in bank capital, and the contraction in credit availability. The Committee therefore is introducing a leverage ratio requirement that is intended to achieve the following objectives:

- $\quad$ constrain leverage in the banking sector, thus helping to mitigate the risk of the destabilising deleveraging processes which can damage the financial system and the economy; and

- $\quad$ introduce additional safeguards against model risk and measurement error by supplementing the risk-based measure with a simple, transparent, independent measure of risk.

17. The leverage ratio is calculated in a comparable manner across jurisdictions, adjusting for any differences in accounting standards. The Committee has designed the leverage ratio to be a credible supplementary measure to the risk-based requirement with a view to migrating to a Pillar 1 treatment based on appropriate review and calibration. 


\section{Reducing procyclicality and promoting countercyclical buffers}

18. One of the most destabilising elements of the crisis has been the procyclical amplification of financial shocks throughout the banking system, financial markets and the broader economy. The tendency of market participants to behave in a procyclical manner has been amplified through a variety of channels, including through accounting standards for both mark-to-market assets and held-to-maturity loans, margining practices, and through the build up and release of leverage among financial institutions, firms, and consumers. The Basel Committee is introducing a number of measures to make banks more resilient to such procyclical dynamics. These measures will help ensure that the banking sector serves as a shock absorber, instead of a transmitter of risk to the financial system and broader economy.

19. In addition to the leverage ratio discussed in the previous section, the Committee is introducing a series of measures to address procyclicality and raise the resilience of the banking sector in good times. These measures have the following key objectives:

- dampen any excess cyclicality of the minimum capital requirement;

- $\quad$ promote more forward looking provisions;

- $\quad$ conserve capital to build buffers at individual banks and the banking sector that can be used in stress; and

- $\quad$ achieve the broader macroprudential goal of protecting the banking sector from periods of excess credit growth.

\section{Cyclicality of the minimum requirement}

20. The Basel II framework increased the risk sensitivity and coverage of the regulatory capital requirement. Indeed, one of the most procyclical dynamics has been the failure of risk management and capital frameworks to capture key exposures - such as complex trading activities, resecuritisations and exposures to off-balance sheet vehicles - in advance of the crisis. However, it is not possible to achieve greater risk sensitivity across institutions at a given point in time without introducing a certain degree of cyclicality in minimum capital requirements over time. The Committee was aware of this trade-off during the design of the Basel II framework and introduced a number of safeguards to address excess cyclicality of the minimum requirement. They include the requirement to use long term data horizons to estimate probabilities of default, the introduction of so called downturn loss-given-default (LGD) estimates and the appropriate calibration of the risk functions, which convert loss estimates into regulatory capital requirements. The Committee also required that banks conduct stress tests that consider the downward migration of their credit portfolios in a recession.

21. In addition, the Committee has put in place a comprehensive data collection initiative to assess the impact of the Basel II framework on its member countries over the credit cycle. Should the cyclicality of the minimum requirement be greater than supervisors consider appropriate, the Committee will consider additional measures to dampen such cyclicality.

22. The Committee has reviewed a number of additional measures that supervisors could take to achieve a better balance between risk sensitivity and the stability of capital requirements, should this be viewed as necessary. In particular, the range of possible measures includes an approach by the Committee of European Banking Supervisors (CEBS) to use the Pillar 2 process to adjust for the compression of probability of default (PD) 
estimates in internal ratings-based (IRB) capital requirements during benign credit conditions by using the PD estimates for a bank's portfolios in downturn conditions. ${ }^{4}$ Addressing the same issue, the UK Financial Services Authority (FSA) has proposed an approach aimed at providing non-cyclical PDs in IRB requirements through the application of a scalar that converts the outputs of a bank's underlying PD models into through-the-cycle estimates. ${ }^{5}$

\section{Forward looking provisioning}

23. The Committee is promoting stronger provisioning practices through three related initiatives. First, it is advocating a change in the accounting standards towards an expected loss (EL) approach. The Committee strongly supports the initiative of the IASB to move to an EL approach. The goal is to improve the usefulness and relevance of financial reporting for stakeholders, including prudential regulators. It has issued publicly and made available to the IASB a set of high level guiding principles that should govern the reforms to the replacement of IAS 39. ${ }^{6}$ The Committee supports an EL approach that captures actual losses more transparently and is also less procyclical than the current "incurred loss" approach.

24. Second, it is updating its supervisory guidance to be consistent with the move to such an EL approach. Such guidance will assist supervisors in promoting strong provisioning practices under the desired EL approach.

25. Third, it is addressing incentives to stronger provisioning in the regulatory capital framework.

\section{Capital conservation}

26. The Committee is introducing a framework to promote the conservation of capital and the build-up of adequate buffers above the minimum that can be drawn down in periods of stress.

27. At the onset of the financial crisis, a number of banks continued to make large distributions in the form of dividends, share buy backs and generous compensation payments even though their individual financial condition and the outlook for the sector were deteriorating. Much of this activity was driven by a collective action problem, where reductions in distributions were perceived as sending a signal of weakness. However, these actions made individual banks and the sector as a whole less resilient. Many banks soon returned to profitability but did not do enough to rebuild their capital buffers to support new lending activity. Taken together, this dynamic has increased the procyclicality of the system.

28. To address this market failure, the Committee is introducing a framework that will give supervisors stronger tools to promote capital conservation in the banking sector. Implementation of the framework through internationally agreed capital conservation standards will help increase sector resilience going into a downturn and will provide the mechanism for rebuilding capital during the economic recovery. Moreover, the framework is

4 See CEBS Position paper on a countercyclical capital buffer (July 2009), available at www.c-ebs.org/getdoc/715bc0f9-7af9-47d9-98a8-778a4d20a880/CEBS-position-paper-on-a-countercyclicalcapital-b.aspx.

5 See UK FSA's note Variable Scalar Approaches to Estimating Through the cycle PDs (February 2009), available at www.fsa.gov.uk/pubs/international/variable_scalars.pdf.

6 See Guiding principles for the revision of accounting standards for financial instruments issued by the Basel Committee (August 2009), available at www.bis.org/press/p090827.htm. 
sufficiently flexible to allow for a range of supervisory and bank responses consistent with the standard.

\section{Excess credit growth}

29. As witnessed during the financial crisis, losses incurred in the banking sector during a downturn preceded by a period of excess credit growth can be extremely large. Such losses can destabilise the banking sector, which can bring about or exacerbate a downturn in the real economy. This in turn can further destabilise the banking sector. These interlinkages highlight the particular importance of the banking sector building up its capital defences in periods when credit has grown to excessive levels. The building up of these defences should have the additional benefit of helping to moderate excess credit growth.

30. The Basel Committee is introducing a regime which will adjust the capital buffer range, established through the capital conservation mechanism outlined in the previous section, when there are signs that credit has grown to excessive levels. The purpose of the countercyclical buffer is to achieve the broader macroprudential goal of protecting the banking sector in periods of excess aggregate credit growth.

31. The measures to address procyclicality are designed to complement each other. The initiatives on provisioning focus on strengthening the banking system against expected losses, while the capital measures focus on unexpected losses. Among the capital measures, there is a distinction between addressing the cyclicality of the minimum and building additional buffers above that minimum. Indeed, strong capital buffers above the minimum requirement have proven to be critical, even in the absence of a cyclical minimum. Finally, the requirement to address excess credit growth is set at zero in normal times and only increases during periods of excessive credit availability. However, even in the absence of a credit bubble, supervisors expect the banking sector to build a buffer above the minimum to protect it against plausibly severe shocks, which could emanate from many sources.

\section{Addressing systemic risk and interconnectedness}

32. While procyclicality amplified shocks over the time dimension, excessive interconnectedness among systemically important banks also transmitted shocks across the financial system and economy. Systemically important banks should have loss absorbing capacity beyond the minimum standards and the work on this issue is ongoing. The Basel Committee and the Financial Stability Board are developing a well integrated approach to systemically important financial institutions which could include combinations of capital surcharges, contingent capital and bail-in debt. As part of this effort, the Committee is developing a proposal on a methodology comprising both quantitative and qualitative indicators to assess the systemic importance of financial institutions at a global level. The Committee is also conducting a study of the magnitude of additional loss absorbency that globally systemic financial institutions should have, along with an assessment of the extent of going concern loss absorbency which could be provided by the various proposed instruments. The Committee's analysis has also covered further measures to mitigate the risks or externalities associated with systemic banks, including liquidity surcharges, tighter large exposure restrictions and enhanced supervision. It will continue its work on these issues in the first half of 2011 in accordance with the processes and timelines set out in the FSB recommendations.

33. Several of the capital requirements introduced by the Committee to mitigate the risks arising from firm-level exposures among global financial institutions will also help to address systemic risk and interconnectedness. These include: 
- capital incentives for banks to use central counterparties for over-the-counter derivatives;

- $\quad$ higher capital requirements for trading and derivative activities, as well as complex securitisations and off-balance sheet exposures (eg structured investment vehicles);

- $\quad$ higher capital requirements for inter-financial sector exposures; and

- $\quad$ the introduction of liquidity requirements that penalise excessive reliance on short term, interbank funding to support longer dated assets.

\section{B. Introducing a global liquidity standard}

34. Strong capital requirements are a necessary condition for banking sector stability but by themselves are not sufficient. A strong liquidity base reinforced through robust supervisory standards is of equal importance. To date, however, there have been no internationally harmonised standards in this area. The Basel Committee is therefore introducing internationally harmonised global liquidity standards. As with the global capital standards, the liquidity standards will establish minimum requirements and will promote an international level playing field to help prevent a competitive race to the bottom.

35. During the early "liquidity phase" of the financial crisis, many banks - despite adequate capital levels - still experienced difficulties because they did not manage their liquidity in a prudent manner. The crisis again drove home the importance of liquidity to the proper functioning of financial markets and the banking sector. Prior to the crisis, asset markets were buoyant and funding was readily available at low cost. The rapid reversal in market conditions illustrated how quickly liquidity can evaporate and that illiquidity can last for an extended period of time. The banking system came under severe stress, which necessitated central bank action to support both the functioning of money markets and, in some cases, individual institutions.

36. The difficulties experienced by some banks were due to lapses in basic principles of liquidity risk management. In response, as the foundation of its liquidity framework, the Committee in 2008 published Principles for Sound Liquidity Risk Management and Supervision. ${ }^{7}$ The Sound Principles provide detailed guidance on the risk management and supervision of funding liquidity risk and should help promote better risk management in this critical area, but only if there is full implementation by banks and supervisors. As such, the Committee will coordinate rigorous follow up by supervisors to ensure that banks adhere to these fundamental principles.

37. To complement these principles, the Committee has further strengthened its liquidity framework by developing two minimum standards for funding liquidity. An additional component of the liquidity framework is a set of monitoring metrics to improve cross-border supervisory consistency.

38. These standards have been developed to achieve two separate but complementary objectives. The first objective is to promote short-term resilience of a bank's liquidity risk profile by ensuring that it has sufficient high quality liquid resources to survive an acute stress scenario lasting for one month. The Committee developed the Liquidity Coverage Ratio (LCR) to achieve this objective. The second objective is to promote resilience over a

\footnotetext{
7 Available at www.bis.org/publ/bcbs144.htm.
} 
longer time horizon by creating additional incentives for a bank to fund its activities with more stable sources of funding on an ongoing structural basis. The Net Stable Funding Ratio (NSFR) has a time horizon of one year and has been developed to provide a sustainable maturity structure of assets and liabilities.

39. These two standards are comprised mainly of specific parameters which are internationally "harmonised" with prescribed values. Certain parameters contain elements of national discretion to reflect jurisdiction-specific conditions. In these cases, the parameters should be transparent and clearly outlined in the regulations of each jurisdiction to provide clarity both within the jurisdiction and internationally.

\section{Liquidity Coverage Ratio}

40. The LCR is intended to promote resilience to potential liquidity disruptions over a thirty day horizon. It will help ensure that global banks have sufficient unencumbered, highquality liquid assets to offset the net cash outflows it could encounter under an acute shortterm stress scenario. The specified scenario is built upon circumstances experienced in the global financial crisis that began in 2007 and entails both institution-specific and systemic shocks. The scenario entails a significant stress, albeit not a worst-case scenario, and assumes the following:

- a significant downgrade of the institution's public credit rating;

- $\quad$ a partial loss of deposits;

- a loss of unsecured wholesale funding;

- $\quad$ a significant increase in secured funding haircuts; and

- $\quad$ increases in derivative collateral calls and substantial calls on contractual and noncontractual off-balance sheet exposures, including committed credit and liquidity facilities.

41. High-quality liquid assets held in the stock should be unencumbered, liquid in markets during a time of stress and, ideally, be central bank eligible.

\section{Net Stable Funding Ratio}

42. The NSFR requires a minimum amount of stable sources of funding at a bank relative to the liquidity profiles of the assets, as well as the potential for contingent liquidity needs arising from off-balance sheet commitments, over a one-year horizon. The NSFR aims to limit over-reliance on short-term wholesale funding during times of buoyant market liquidity and encourage better assessment of liquidity risk across all on- and off-balance sheet items.

\section{Monitoring tools}

43. At present, supervisors use a wide range of quantitative measures to monitor the liquidity risk profiles of banking organisations as well as across the financial sector, for a macroprudential approach to supervision. A survey of Basel Committee members conducted in early 2009 identified that more than 25 different measures and concepts are used globally by supervisors. To introduce more consistency internationally, the Committee has developed a set of common metrics that should be considered as the minimum types of information which supervisors should use. In addition, supervisors may use additional metrics in order to capture specific risks in their jurisdictions. The monitoring metrics include the following and 
may evolve further as the Committee conducts further work. One area in particular where more work on monitoring tools will be conducted relates to intraday liquidity risk.

(a) Contractual maturity mismatch: To gain an understanding of the basic aspects of a bank's liquidity needs, banks should frequently conduct a contractual maturity mismatch assessment. This metric provides an initial, simple baseline of contractual commitments and is useful in comparing liquidity risk profiles across institutions, and to highlight to both banks and supervisors when potential liquidity needs could arise.

(b) Concentration of funding: This metric involves analysing concentrations of wholesale funding provided by specific counterparties, instruments and currencies. A metric covering concentrations of wholesale funding assists supervisors in assessing the extent to which funding liquidity risks could occur in the event that one or more of the funding sources are withdrawn.

(c) Available unencumbered assets: This metric measures the amount of unencumbered assets a bank has which could potentially be used as collateral for secured funding either in the market or at standing central bank facilities. This should make banks (and supervisors) more aware of their potential capacity to raise additional secured funds, keeping in mind that in a stressed situation this ability may decrease.

(d) LCR by currency: In recognition that foreign exchange risk is a component of liquidity risk, the LCR should also be assessed in each significant currency, in order to monitor and manage the overall level and trend of currency exposure at a bank.

(e) Market-related monitoring tools: In order to have a source of instantaneous data on potential liquidity difficulties, useful data to monitor includes market-wide data on asset prices and liquidity, institution-related information such as credit default swap (CDS) spreads and equity prices, and additional institution-specific information related to the ability of the institution to fund itself in various wholesale funding markets and the price at which it can do so.

\section{Transitional arrangements}

44. The Committee is introducing transitional arrangements to implement the new standards that help ensure that the banking sector can meet the higher capital standards through reasonable earnings retention and capital raising, while still supporting lending to the economy. The transitional arrangements are described in the Basel III liquidity rules text document and summarised in Annex 4 of this document.

45. After an observation period beginning in 2011, the LCR will be introduced on 1 January 2015. The NSFR will move to a minimum standard by 1 January 2018. The Committee will put in place rigorous reporting processes to monitor the ratios during the transition period and will continue to review the implications of these standards for financial markets, credit extension and economic growth, addressing unintended consequences as necessary.

46. Both the LCR and the NSFR will be subject to an observation period and will include a review clause to address any unintended consequences. 


\section{Scope of application}

47. The application of the minimum capital requirements in this document follow the existing scope of application set out in Part I (Scope of Application) of the Basel II Framework. $^{8}$

8 See BCBS, International Convergence of Capital Measurement and Capital Standards, June 2006 (hereinafter referred to as "Basel II" or "Basel II Framework"). 


\section{Part 1: Minimum capital requirements and buffers}

48. The global banking system entered the crisis with an insufficient level of high quality capital. The crisis also revealed the inconsistency in the definition of capital across jurisdictions and the lack of disclosure that would have enabled the market to fully assess and compare the quality of capital across jurisdictions. A key element of the new definition of capital is the greater focus on common equity, the highest quality component of a bank's capital.

\section{Definition of capital}

\section{A. Components of capital}

\section{Elements of capital}

49. Total regulatory capital will consist of the sum of the following elements:

1. Tier 1 Capital (going-concern capital)
a. Common Equity Tier 1
b. Additional Tier 1

2. Tier 2 Capital (gone-concern capital)

For each of the three categories above $(1 a, 1 b$ and 2$)$ there is a single set of criteria that instruments are required to meet before inclusion in the relevant category. ${ }^{9}$

\section{Limits and minima}

50. All elements above are net of the associated regulatory adjustments and are subject to the following restrictions (see also Annex 1):

- $\quad$ Common Equity Tier 1 must be at least $4.5 \%$ of risk-weighted assets at all times.

- $\quad$ Tier 1 Capital must be at least $6.0 \%$ of risk-weighted assets at all times.

- $\quad$ Total Capital (Tier 1 Capital plus Tier 2 Capital) must be at least $8.0 \%$ of riskweighted assets at all times.

\section{B. Detailed proposal}

51. Throughout this section the term "bank" is used to mean bank, banking group or other entity (eg holding company) whose capital is being measured.

9 As set out in the Committee's August 2010 consultative document, Proposal to ensure the loss absorbency of regulatory capital at the point of non-viability, and as stated in the Committee's 19 October 2010 and 1 December 2010 press releases, the Committee is finalising additional entry criteria for Additional Tier 1 and Tier 2 capital. Once finalised, the additional criteria will be added to this regulatory framework. 


\section{Common Equity Tier 1}

52. Common Equity Tier 1 capital consists of the sum of the following elements:

- Common shares issued by the bank that meet the criteria for classification as common shares for regulatory purposes (or the equivalent for non-joint stock companies);

- $\quad$ Stock surplus (share premium) resulting from the issue of instruments included Common Equity Tier 1;

- $\quad$ Retained earnings;

- $\quad$ Accumulated other comprehensive income and other disclosed reserves; ${ }^{10}$

- $\quad$ Common shares issued by consolidated subsidiaries of the bank and held by third parties (ie minority interest) that meet the criteria for inclusion in Common Equity Tier 1 capital. See section 4 for the relevant criteria; and

- $\quad$ Regulatory adjustments applied in the calculation of Common Equity Tier 1

Retained earnings and other comprehensive income include interim profit or loss. National authorities may consider appropriate audit, verification or review procedures. Dividends are removed from Common Equity Tier 1 in accordance with applicable accounting standards. The treatment of minority interest and the regulatory adjustments applied in the calculation of Common Equity Tier 1 are addressed in separate sections.

\section{Common shares issued by the bank}

53. For an instrument to be included in Common Equity Tier 1 capital it must meet all of the criteria that follow. The vast majority of internationally active banks are structured as joint stock companies ${ }^{11}$ and for these banks the criteria must be met solely with common shares. In the rare cases where banks need to issue non-voting common shares as part of Common Equity Tier 1, they must be identical to voting common shares of the issuing bank in all respects except the absence of voting rights.

10 There is no adjustment applied to remove from Common Equity Tier 1 unrealised gains or losses recognised on the balance sheet. Unrealised losses are subject to the transitional arrangements set out in paragraph 94 (c) and (d). The Committee will continue to review the appropriate treatment of unrealised gains, taking into account the evolution of the accounting framework.

11 Joint stock companies are defined as companies that have issued common shares, irrespective of whether these shares are held privately or publically. These will represent the vast majority of internationally active banks. 


\section{Criteria for classification as common shares for regulatory capital purposes ${ }^{12}$}

1. Represents the most subordinated claim in liquidation of the bank.

2. Entitled to a claim on the residual assets that is proportional with its share of issued capital, after all senior claims have been repaid in liquidation (ie has an unlimited and variable claim, not a fixed or capped claim).

3. Principal is perpetual and never repaid outside of liquidation (setting aside discretionary repurchases or other means of effectively reducing capital in a discretionary manner that is allowable under relevant law).

4. The bank does nothing to create an expectation at issuance that the instrument will be bought back, redeemed or cancelled nor do the statutory or contractual terms provide any feature which might give rise to such an expectation.

5. Distributions are paid out of distributable items (retained earnings included). The level of distributions is not in any way tied or linked to the amount paid in at issuance and is not subject to a contractual cap (except to the extent that a bank is unable to pay distributions that exceed the level of distributable items).

6. There are no circumstances under which the distributions are obligatory. Non payment is therefore not an event of default.

7. Distributions are paid only after all legal and contractual obligations have been met and payments on more senior capital instruments have been made. This means that there are no preferential distributions, including in respect of other elements classified as the highest quality issued capital.

8. It is the issued capital that takes the first and proportionately greatest share of any losses as they occur ${ }^{13}$. Within the highest quality capital, each instrument absorbs losses on a going concern basis proportionately and pari passu with all the others.

9. The paid in amount is recognised as equity capital (ie not recognised as a liability) for determining balance sheet insolvency.

10. The paid in amount is classified as equity under the relevant accounting standards.

11. It is directly issued and paid-in and the bank can not directly or indirectly have funded the purchase of the instrument.

12 The criteria also apply to non joint stock companies, such as mutuals, cooperatives or savings institutions, taking into account their specific constitution and legal structure. The application of the criteria should preserve the quality of the instruments by requiring that they are deemed fully equivalent to common shares in terms of their capital quality as regards loss absorption and do not possess features which could cause the condition of the bank to be weakened as a going concern during periods of market stress. Supervisors will exchange information on how they apply the criteria to non joint stock companies in order to ensure consistent implementation.

13 In cases where capital instruments have a permanent write-down feature, this criterion is still deemed to be met by common shares. 
12. The paid in amount is neither secured nor covered by a guarantee of the issuer or related entity ${ }^{14}$ or subject to any other arrangement that legally or economically enhances the seniority of the claim.

13. It is only issued with the approval of the owners of the issuing bank, either given directly by the owners or, if permitted by applicable law, given by the Board of Directors or by other persons duly authorised by the owners.

14. It is clearly and separately disclosed on the bank's balance sheet.

\section{Additional Tier 1 capital}

54. Additional Tier 1 capital consists of the sum of the following elements:

- Instruments issued by the bank that meet the criteria for inclusion in Additional Tier 1 capital (and are not included in Common Equity Tier 1);

- $\quad$ Stock surplus (share premium) resulting from the issue of instruments included in Additional Tier 1 capital;

- Instruments issued by consolidated subsidiaries of the bank and held by third parties that meet the criteria for inclusion in Additional Tier 1 capital and are not included in Common Equity Tier 1. See section 4 for the relevant criteria; and

- $\quad$ Regulatory adjustments applied in the calculation of Additional Tier 1 Capital

The treatment of instruments issued out of consolidated subsidiaries of the bank and the regulatory adjustments applied in the calculation of Additional Tier 1 Capital are addressed in separate sections.

Instruments issued by the bank that meet the Additional Tier 1 criteria

55. The following box sets out the minimum set of criteria for an instrument issued by the bank to meet or exceed in order for it to be included in Additional Tier 1 capital.

\section{Criteria for inclusion in Additional Tier 1 capital}

1. Issued and paid-in

2. Subordinated to depositors, general creditors and subordinated debt of the bank

3. Is neither secured nor covered by a guarantee of the issuer or related entity or other arrangement that legally or economically enhances the seniority of the claim vis-à-vis bank creditors

4. Is perpetual, ie there is no maturity date and there are no step-ups or other incentives to redeem

14 A related entity can include a parent company, a sister company, a subsidiary or any other affiliate. A holding company is a related entity irrespective of whether it forms part of the consolidated banking group. 
5. May be callable at the initiative of the issuer only after a minimum of five years:

a. To exercise a call option a bank must receive prior supervisory approval; and

b. A bank must not do anything which creates an expectation that the call will be exercised; and

c. Banks must not exercise a call unless:

i. They replace the called instrument with capital of the same or better quality and the replacement of this capital is done at conditions which are sustainable for the income capacity of the bank ${ }^{15}$; or

ii. The bank demonstrates that its capital position is well above the minimum capital requirements after the call option is exercised. ${ }^{16}$

6. Any repayment of principal (eg through repurchase or redemption) must be with prior supervisory approval and banks should not assume or create market expectations that supervisory approval will be given

7. Dividend/coupon discretion:

a. the bank must have full discretion at all times to cancel distributions/payments ${ }^{17}$

b. cancellation of discretionary payments must not be an event of default

c. banks must have full access to cancelled payments to meet obligations as they fall due

d. cancellation of distributions/payments must not impose restrictions on the bank except in relation to distributions to common stockholders.

8. Dividends/coupons must be paid out of distributable items

9. The instrument cannot have a credit sensitive dividend feature, that is a dividend/coupon that is reset periodically based in whole or in part on the banking organisation's credit standing.

10. The instrument cannot contribute to liabilities exceeding assets if such a balance sheet test forms part of national insolvency law.

15 Replacement issues can be concurrent with but not after the instrument is called.

16 Minimum refers to the regulator's prescribed minimum requirement, which may be higher than the Basel III Pillar 1 minimum requirement.

17 A consequence of full discretion at all times to cancel distributions/payments is that "dividend pushers" are prohibited. An instrument with a dividend pusher obliges the issuing bank to make a dividend/coupon payment on the instrument if it has made a payment on another (typically more junior) capital instrument or share. This obligation is inconsistent with the requirement for full discretion at all times. Furthermore, the term "cancel distributions/payments" means extinguish these payments. It does not permit features that require the bank to make distributions/payments in kind. 
11. Instruments classified as liabilities for accounting purposes must have principal loss absorption through either (i) conversion to common shares at an objective pre-specified trigger point or (ii) a write-down mechanism which allocates losses to the instrument at a pre-specified trigger point. The write-down will have the following effects:

a. Reduce the claim of the instrument in liquidation;

b. Reduce the amount re-paid when a call is exercised; and

c. Partially or fully reduce coupon/dividend payments on the instrument.

12. Neither the bank nor a related party over which the bank exercises control or significant influence can have purchased the instrument, nor can the bank directly or indirectly have funded the purchase of the instrument

13. The instrument cannot have any features that hinder recapitalisation, such as provisions that require the issuer to compensate investors if a new instrument is issued at a lower price during a specified time frame

14. If the instrument is not issued out of an operating entity or the holding company in the consolidated group (eg a special purpose vehicle - "SPV"), proceeds must be immediately available without limitation to an operating entity ${ }^{18}$ or the holding company in the consolidated group in a form which meets or exceeds all of the other criteria for inclusion in Additional Tier 1 capital

Stock surplus (share premium) resulting from the issue of instruments included in Additional Tier 1 capital;

56. Stock surplus (ie share premium) that is not eligible for inclusion in Common Equity Tier 1, will only be permitted to be included in Additional Tier 1 capital if the shares giving rise to the stock surplus are permitted to be included in Additional Tier 1 capital.

\section{Tier 2 capital}

57. Tier 2 capital consists of the sum of the following elements:

- Instruments issued by the bank that meet the criteria for inclusion in Tier 2 capital (and are not included in Tier 1 capital);

- $\quad$ Stock surplus (share premium) resulting from the issue of instruments included in Tier 2 capital;

- Instruments issued by consolidated subsidiaries of the bank and held by third parties that meet the criteria for inclusion in Tier 2 capital and are not included in Tier 1 capital. See section 4 for the relevant criteria;

- $\quad$ Certain loan loss provisions as specified in paragraphs 60 and 61; and

- $\quad$ Regulatory adjustments applied in the calculation of Tier 2 Capital.

18 An operating entity is an entity set up to conduct business with clients with the intention of earning a profit in its own right. 
The treatment of instruments issued out of consolidated subsidiaries of the bank and the regulatory adjustments applied in the calculation of Tier 2 Capital are addressed in separate sections.

\section{Instruments issued by the bank that meet the Tier 2 criteria}

58. The objective of Tier 2 is to provide loss absorption on a gone-concern basis. Based on this objective, the following box sets out the minimum set of criteria for an instrument to meet or exceed in order for it to be included in Tier 2 capital.

\section{Criteria for inclusion in Tier 2 Capital}

1. Issued and paid-in

2. Subordinated to depositors and general creditors of the bank

3. Is neither secured nor covered by a guarantee of the issuer or related entity or other arrangement that legally or economically enhances the seniority of the claim vis-à-vis depositors and general bank creditors

4. Maturity:

a. minimum original maturity of at least five years

b. recognition in regulatory capital in the remaining five years before maturity will be amortised on a straight line basis

c. there are no step-ups or other incentives to redeem

5. May be callable at the initiative of the issuer only after a minimum of five years:

a. To exercise a call option a bank must receive prior supervisory approval;

b. A bank must not do anything that creates an expectation that the call will be exercised; ${ }^{19}$ and

c. Banks must not exercise a call unless:

i. They replace the called instrument with capital of the same or better quality and the replacement of this capital is done at conditions which are sustainable for the income capacity of the bank ${ }^{20}$; or

ii. The bank demonstrates that its capital position is well above the minimum capital requirements after the call option is exercised. ${ }^{21}$

6. The investor must have no rights to accelerate the repayment of future scheduled payments (coupon or principal), except in bankruptcy and liquidation.

19 An option to call the instrument after five years but prior to the start of the amortisation period will not be viewed as an incentive to redeem as long as the bank does not do anything that creates an expectation that the call will be exercised at this point.

20 Replacement issues can be concurrent with but not after the instrument is called.

21 Minimum refers to the regulator's prescribed minimum requirement, which may be higher than the Basel III Pillar 1 minimum requirement. 
7. The instrument cannot have a credit sensitive dividend feature, that is a dividend/coupon that is reset periodically based in whole or in part on the banking organisation's credit standing.

8. Neither the bank nor a related party over which the bank exercises control or significant influence can have purchased the instrument, nor can the bank directly or indirectly have funded the purchase of the instrument

9. If the instrument is not issued out of an operating entity or the holding company in the consolidated group (eg a special purpose vehicle - "SPV"), proceeds must be immediately available without limitation to an operating entity ${ }^{22}$ or the holding company in the consolidated group in a form which meets or exceeds all of the other criteria for inclusion in Tier 2 Capital

Stock surplus (share premium) resulting from the issue of instruments included in Tier 2 capital;

59. Stock surplus (ie share premium) that is not eligible for inclusion in Tier 1, will only be permitted to be included in Tier 2 capital if the shares giving rise to the stock surplus are permitted to be included in Tier 2 capital.

General provisions/general loan-loss reserves (for banks using the Standardised Approach for credit risk)

60. Provisions or loan-loss reserves held against future, presently unidentified losses are freely available to meet losses which subsequently materialise and therefore qualify for inclusion within Tier 2. Provisions ascribed to identified deterioration of particular assets or known liabilities, whether individual or grouped, should be excluded. Furthermore, general provisions/general loan-loss reserves eligible for inclusion in Tier 2 will be limited to a maximum of 1.25 percentage points of credit risk-weighted risk assets calculated under the standardised approach.

\section{Excess of total eligible provisions under the Internal Ratings-based Approach}

61. Where the total expected loss amount is less than total eligible provisions, as explained in paragraphs 380 to 383 of the June 2006 Comprehensive version of Basel II, banks may recognise the difference in Tier 2 capital up to a maximum of $0.6 \%$ of credit riskweighted assets calculated under the IRB approach. At national discretion, a limit lower than $0.6 \%$ may be applied.

\section{Minority interest (ie non-controlling interest) and other capital issued out of consolidated subsidiaries that is held by third parties}

Common shares issued by consolidated subsidiaries

62. Minority interest arising from the issue of common shares by a fully consolidated subsidiary of the bank may receive recognition in Common Equity Tier 1 only if: (1) the instrument giving rise to the minority interest would, if issued by the bank, meet all of the

22 An operating entity is an entity set up to conduct business with clients with the intention of earning a profit in its own right. 
criteria for classification as common shares for regulatory capital purposes; and (2) the subsidiary that issued the instrument is itself a bank. ${ }^{23,24}$ The amount of minority interest meeting the criteria above that will be recognised in consolidated Common Equity Tier 1 will be calculated as follows:

- $\quad$ Total minority interest meeting the two criteria above minus the amount of the surplus Common Equity Tier 1 of the subsidiary attributable to the minority shareholders.

- $\quad$ Surplus Common Equity Tier 1 of the subsidiary is calculated as the Common Equity Tier 1 of the subsidiary minus the lower of: (1) the minimum Common Equity Tier 1 requirement of the subsidiary plus the capital conservation buffer (ie $7.0 \%$ of risk weighted assets) and (2) the portion of the consolidated minimum Common Equity Tier 1 requirement plus the capital conservation buffer (ie $7.0 \%$ of consolidated risk weighted assets) that relates to the subsidiary.

- $\quad$ The amount of the surplus Common Equity Tier 1 that is attributable to the minority shareholders is calculated by multiplying the surplus Common Equity Tier 1 by the percentage of Common Equity Tier 1 that is held by minority shareholders.

\section{Tier 1 qualifying capital issued by consolidated subsidiaries}

63. Tier 1 capital instruments issued by a fully consolidated subsidiary of the bank to third party investors (including amounts under paragraph 62) may receive recognition in Tier 1 capital only if the instruments would, if issued by the bank, meet all of the criteria for classification as Tier 1 capital. The amount of this capital that will be recognised in Tier 1 will be calculated as follows:

- $\quad$ Total Tier 1 of the subsidiary issued to third parties minus the amount of the surplus Tier 1 of the subsidiary attributable to the third party investors.

- $\quad$ Surplus Tier 1 of the subsidiary is calculated as the Tier 1 of the subsidiary minus the lower of: (1) the minimum Tier 1 requirement of the subsidiary plus the capital conservation buffer (ie $8.5 \%$ of risk weighted assets) and (2) the portion of the consolidated minimum Tier 1 requirement plus the capital conservation buffer (ie $8.5 \%$ of consolidated risk weighted assets) that relates to the subsidiary.

- $\quad$ The amount of the surplus Tier 1 that is attributable to the third party investors is calculated by multiplying the surplus Tier 1 by the percentage of Tier 1 that is held by third party investors.

The amount of this Tier 1 capital that will be recognised in Additional Tier 1 will exclude amounts recognised in Common Equity Tier 1 under paragraph 62.

23 For the purposes of this paragraph, any institution that is subject to the same minimum prudential standards and level of supervision as a bank may be considered to be a bank.

24 Minority interest in a subsidiary that is a bank is strictly excluded from the parent bank's common equity if the parent bank or affiliate has entered into any arrangements to fund directly or indirectly minority investment in the subsidiary whether through an SPV or through another vehicle or arrangement. The treatment outlined above, thus, is strictly available where all minority investments in the bank subsidiary solely represent genuine third party common equity contributions to the subsidiary. 
Tier 1 and Tier 2 qualifying capital issued by consolidated subsidiaries

64. Total capital instruments (ie Tier 1 and Tier 2 capital instruments) issued by a fully consolidated subsidiary of the bank to third party investors (including amounts under paragraph 62 and 63) may receive recognition in Total Capital only if the instruments would, if issued by the bank, meet all of the criteria for classification as Tier 1 or Tier 2 capital. The amount of this capital that will be recognised in consolidated Total Capital will be calculated as follows:

- Total capital instruments of the subsidiary issued to third parties minus the amount of the surplus Total Capital of the subsidiary attributable to the third party investors.

- $\quad$ Surplus Total Capital of the subsidiary is calculated as the Total Capital of the subsidiary minus the lower of: (1) the minimum Total Capital requirement of the subsidiary plus the capital conservation buffer (ie 10.5\% of risk weighted assets) and (2) the portion of the consolidated minimum Total Capital requirement plus the capital conservation buffer (ie $10.5 \%$ of consolidated risk weighted assets) that relates to the subsidiary.

- The amount of the surplus Total Capital that is attributable to the third party investors is calculated by multiplying the surplus Total Capital by the percentage of Total Capital that is held by third party investors.

The amount of this Total Capital that will be recognised in Tier 2 will exclude amounts recognised in Common Equity Tier 1 under paragraph 62 and amounts recognised in Additional Tier 1 under paragraph 63.

65. Where capital has been issued to third parties out of a special purpose vehicle (SPV), none of this capital can be included in Common Equity Tier 1. However, such capital can be included in consolidated Additional Tier 1 or Tier 2 and treated as if the bank itself had issued the capital directly to the third parties only if it meets all the relevant entry criteria and the only asset of the SPV is its investment in the capital of the bank in a form that meets or exceeds all the relevant entry criteria ${ }^{25}$ (as required by criterion 14 for Additional Tier 1 and criterion 9 for Tier 2). In cases where the capital has been issued to third parties through an SPV via a fully consolidated subsidiary of the bank, such capital may, subject to the requirements of this paragraph, be treated as if the subsidiary itself had issued it directly to the third parties and may be included in the bank's consolidated Additional Tier 1 or Tier 2 in accordance with the treatment outlined in paragraphs 63 and 64.

\section{Regulatory adjustments}

66. This section sets out the regulatory adjustments to be applied to regulatory capital. In most cases these adjustments are applied in the calculation of Common Equity Tier 1.

\section{Goodwill and other intangibles (except mortgage servicing rights)}

67. Goodwill and all other intangibles must be deducted in the calculation of Common Equity Tier 1, including any goodwill included in the valuation of significant investments in the capital of banking, financial and insurance entities that are outside the scope of regulatory consolidation. With the exception of mortgage servicing rights, the full amount is to be deducted net of any associated deferred tax liability which would be extinguished if the

25 Assets that relate to the operation of the SPV may be excluded from this assessment if they are de minimis. 
intangible assets become impaired or derecognised under the relevant accounting standards. The amount to be deducted in respect of mortgage servicing rights is set out in the threshold deductions section below.

68. Subject to prior supervisory approval, banks that report under local GAAP may use the IFRS definition of intangible assets to determine which assets are classified as intangible and are thus required to be deducted.

\section{Deferred tax assets}

69. Deferred tax assets (DTAs) that rely on future profitability of the bank to be realised are to be deducted in the calculation of Common Equity Tier 1. Deferred tax assets may be netted with associated deferred tax liabilities (DTLs) only if the DTAs and DTLs relate to taxes levied by the same taxation authority and offsetting is permitted by the relevant taxation authority. Where these DTAs relate to temporary differences (eg allowance for credit losses) the amount to be deducted is set out in the "threshold deductions" section below. All other such assets, eg those relating to operating losses, such as the carry forward of unused tax losses, or unused tax credits, are to be deducted in full net of deferred tax liabilities as described above. The DTLs permitted to be netted against DTAs must exclude amounts that have been netted against the deduction of goodwill, intangibles and defined benefit pension assets, and must be allocated on a pro rata basis between DTAs subject to the threshold deduction treatment and DTAs that are to be deducted in full.

70. An overinstallment of tax or, in some jurisdictions, current year tax losses carried back to prior years may give rise to a claim or receivable from the government or local tax authority. Such amounts are typically classified as current tax assets for accounting purposes. The recovery of such a claim or receivable would not rely on the future profitability of the bank and would be assigned the relevant sovereign risk weighting.

\section{Cash flow hedge reserve}

71. The amount of the cash flow hedge reserve that relates to the hedging of items that are not fair valued on the balance sheet (including projected cash flows) should be derecognised in the calculation of Common Equity Tier 1 . This means that positive amounts should be deducted and negative amounts should be added back.

72. This treatment specifically identifies the element of the cash flow hedge reserve that is to be derecognised for prudential purposes. It removes the element that gives rise to artificial volatility in common equity, as in this case the reserve only reflects one half of the picture (the fair value of the derivative, but not the changes in fair value of the hedged future cash flow).

\section{Shortfall of the stock of provisions to expected losses}

73. The deduction from capital in respect of a shortfall of the stock of provisions to expected losses under the IRB approach should be made in the calculation of Common Equity Tier 1. The full amount is to be deducted and should not be reduced by any tax effects that could be expected to occur if provisions were to rise to the level of expected losses.

\section{Gain on sale related to securitisation transactions}

74. Derecognise in the calculation of Common Equity Tier 1 any increase in equity capital resulting from a securitisation transaction, such as that associated with expected future margin income $(\mathrm{FMI})$ resulting in a gain-on-sale. 
Cumulative gains and losses due to changes in own credit risk on fair valued financial liabilities

75. Derecognise in the calculation of Common Equity Tier 1, all unrealised gains and losses that have resulted from changes in the fair value of liabilities that are due to changes in the bank's own credit risk.

\section{Defined benefit pension fund assets and liabilities}

76. Defined benefit pension fund liabilities, as included on the balance sheet, must be fully recognised in the calculation of Common Equity Tier 1 (ie Common Equity Tier 1 cannot be increased through derecognising these liabilities). For each defined benefit pension fund that is an asset on the balance sheet, the asset should be deducted in the calculation of Common Equity Tier 1 net of any associated deferred tax liability which would be extinguished if the asset should become impaired or derecognised under the relevant accounting standards. Assets in the fund to which the bank has unrestricted and unfettered access can, with supervisory approval, offset the deduction. Such offsetting assets should be given the risk weight they would receive if they were owned directly by the bank.

77. This treatment addresses the concern that assets arising from pension funds may not be capable of being withdrawn and used for the protection of depositors and other creditors of a bank. The concern is that their only value stems from a reduction in future payments into the fund. The treatment allows for banks to reduce the deduction of the asset if they can address these concerns and show that the assets can be easily and promptly withdrawn from the fund.

\section{Investments in own shares (treasury stock)}

78. All of a bank's investments in its own common shares, whether held directly or indirectly, will be deducted in the calculation of Common Equity Tier 1 (unless already derecognised under the relevant accounting standards). In addition, any own stock which the bank could be contractually obliged to purchase should be deducted in the calculation of Common Equity Tier 1. The treatment described will apply irrespective of the location of the exposure in the banking book or the trading book. In addition:

- $\quad$ Gross long positions may be deducted net of short positions in the same underlying exposure only if the short positions involve no counterparty risk.

- $\quad$ Banks should look through holdings of index securities to deduct exposures to own shares. However, gross long positions in own shares resulting from holdings of index securities may be netted against short position in own shares resulting from short positions in the same underlying index. In such cases the short positions may involve counterparty risk (which will be subject to the relevant counterparty credit risk charge).

This deduction is necessary to avoid the double counting of a bank's own capital. Certain accounting regimes do not permit the recognition of treasury stock and so this deduction is only relevant where recognition on the balance sheet is permitted. The treatment seeks to remove the double counting that arises from direct holdings, indirect holdings via index funds and potential future holdings as a result of contractual obligations to purchase own shares.

Following the same approach outlined above, banks must deduct investments in their own Additional Tier 1 in the calculation of their Additional Tier 1 capital and must deduct investments in their own Tier 2 in the calculation of their Tier 2 capital. 
79. Reciprocal cross holdings of capital that are designed to artificially inflate the capital position of banks will be deducted in full. Banks must apply a "corresponding deduction approach" to such investments in the capital of other banks, other financial institutions and insurance entities. This means the deduction should be applied to the same component of capital for which the capital would qualify if it was issued by the bank itself.

Investments in the capital of banking, financial and insurance entities that are outside the scope of regulatory consolidation and where the bank does not own more than $10 \%$ of the issued common share capital of the entity

80. The regulatory adjustment described in this section applies to investments in the capital of banking, financial and insurance entities that are outside the scope of regulatory consolidation and where the bank does not own more than $10 \%$ of the issued common share capital of the entity. In addition:

- Investments include direct, indirect ${ }^{26}$ and synthetic holdings of capital instruments. For example, banks should look through holdings of index securities to determine their underlying holdings of capital. ${ }^{27}$

- Holdings in both the banking book and trading book are to be included. Capital includes common stock and all other types of cash and synthetic capital instruments (eg subordinated debt). It is the net long position that is to be included (ie the gross long position net of short positions in the same underlying exposure where the maturity of the short position either matches the maturity of the long position or has a residual maturity of at least one year).

- $\quad$ Underwriting positions held for five working days or less can be excluded. Underwriting positions held for longer than five working days must be included.

- If the capital instrument of the entity in which the bank has invested does not meet the criteria for Common Equity Tier 1, Additional Tier 1, or Tier 2 capital of the bank, the capital is to be considered common shares for the purposes of this regulatory adjustment. $^{28}$

- National discretion applies to allow banks, with prior supervisory approval, to exclude temporarily certain investments where these have been made in the context of resolving or providing financial assistance to reorganise a distressed institution.

81. If the total of all holdings listed above in aggregate exceed $10 \%$ of the bank's common equity (after applying all other regulatory adjustments in full listed prior to this one) then the amount above $10 \%$ is required to be deducted, applying a corresponding deduction approach. This means the deduction should be applied to the same component of capital for which the capital would qualify if it was issued by the bank itself. Accordingly, the amount to be deducted from common equity should be calculated as the total of all holdings which in aggregate exceed $10 \%$ of the bank's common equity (as per above) multiplied by the

26 Indirect holdings are exposures or parts of exposures that, if a direct holding loses its value, will result in a loss to the bank substantially equivalent to the loss in value of the direct holding.

27 If banks find it operationally burdensome to look through and monitor their exact exposure to the capital of other financial institutions as a result of their holdings of index securities, national authorities may permit banks, subject to prior supervisory approval, to use a conservative estimate.

28 If the investment is issued out of a regulated financial entity and not included in regulatory capital in the relevant sector of the financial entity, it is not required to be deducted. 
common equity holdings as a percentage of the total capital holdings. This would result in a common equity deduction which corresponds to the proportion of total capital holdings held in common equity. Similarly, the amount to be deducted from Additional Tier 1 capital should be calculated as the total of all holdings which in aggregate exceed $10 \%$ of the bank's common equity (as per above) multiplied by the Additional Tier 1 capital holdings as a percentage of the total capital holdings. The amount to be deducted from Tier 2 capital should be calculated as the total of all holdings which in aggregate exceed $10 \%$ of the bank's common equity (as per above) multiplied by the Tier 2 capital holdings as a percentage of the total capital holdings.

82. If, under the corresponding deduction approach, a bank is required to make a deduction from a particular tier of capital and it does not have enough of that tier of capital to satisfy that deduction, the shortfall will be deducted from the next higher tier of capital (eg if a bank does not have enough Additional Tier 1 capital to satisfy the deduction, the shortfall will be deducted from Common Equity Tier 1).

83. Amounts below the threshold, which are not deducted, will continue to be risk weighted. Thus, instruments in the trading book will be treated as per the market risk rules and instruments in the banking book should be treated as per the internal ratings-based approach or the standardised approach (as applicable). For the application of risk weighting the amount of the holdings must be allocated on a pro rata basis between those below and those above the threshold.

\section{Significant investments in the capital of banking, financial and insurance entities that are} outside the scope of regulatory consolidation ${ }^{29}$

84. The regulatory adjustment described in this section applies to investments in the capital of banking, financial and insurance entities that are outside the scope of regulatory consolidation where the bank owns more than $10 \%$ of the issued common share capital of the issuing entity or where the entity is an affiliate ${ }^{30}$ of the bank. In addition:

- Investments include direct, indirect and synthetic holdings of capital instruments. For example, banks should look through holdings of index securities to determine their underlying holdings of capital. ${ }^{31}$

- $\quad$ Holdings in both the banking book and trading book are to be included. Capital includes common stock and all other types of cash and synthetic capital instruments (eg subordinated debt). It is the net long position that is to be included (ie the gross long position net of short positions in the same underlying exposure where the maturity of the short position either matches the maturity of the long position or has a residual maturity of at least one year).

29 Investments in entities that are outside of the scope of regulatory consolidation refers to investments in entities that have not been consolidated at all or have not been consolidated in such a way as to result in their assets being included in the calculation of consolidated risk-weighted assets of the group.

30 An affiliate of a bank is defined as a company that controls, or is controlled by, or is under common control with, the bank. Control of a company is defined as (1) ownership, control, or holding with power to vote $20 \%$ or more of a class of voting securities of the company; or (2) consolidation of the company for financial reporting purposes.

31 If banks find it operationally burdensome to look through and monitor their exact exposure to the capital of other financial institutions as a result of their holdings of index securities, national authorities may permit banks, subject to prior supervisory approval, to use a conservative estimate. 
- $\quad$ Underwriting positions held for five working days or less can be excluded. Underwriting positions held for longer than five working days must be included.

- If the capital instrument of the entity in which the bank has invested does not meet the criteria for Common Equity Tier 1, Additional Tier 1, or Tier 2 capital of the bank, the capital is to be considered common shares for the purposes of this regulatory adjustment. ${ }^{32}$

- National discretion applies to allow banks, with prior supervisory approval, to exclude temporarily certain investments where these have been made in the context of resolving or providing financial assistance to reorganise a distressed institution.

85. All investments included above that are not common shares must be fully deducted following a corresponding deduction approach. This means the deduction should be applied to the same tier of capital for which the capital would qualify if it was issued by the bank itself. If the bank is required to make a deduction from a particular tier of capital and it does not have enough of that tier of capital to satisfy that deduction, the shortfall will be deducted from the next higher tier of capital (eg if a bank does not have enough Additional Tier 1 capital to satisfy the deduction, the shortfall will be deducted from Common Equity Tier 1).

86. Investments included above that are common shares will be subject to the threshold treatment described in the next section.

\section{Threshold deductions}

87. Instead of a full deduction, the following items may each receive limited recognition when calculating Common Equity Tier 1, with recognition capped at $10 \%$ of the bank's common equity (after the application of all regulatory adjustments set out in paragraphs 67 to 85):

- Significant investments in the common shares of unconsolidated financial institutions (banks, insurance and other financial entities) as referred to in paragraph 84 ;

- $\quad$ Mortgage servicing rights (MSRs); and

- $\quad$ DTAs that arise from temporary differences.

88. On 1 January 2013, a bank must deduct the amount by which the aggregate of the three items above exceeds $15 \%$ of its common equity component of Tier 1 (calculated prior to the deduction of these items but after application of all other regulatory adjustments applied in the calculation of Common Equity Tier 1). The items included in the 15\% aggregate limit are subject to full disclosure. As of 1 January 2018, the calculation of the $15 \%$ limit will be subject to the following treatment: the amount of the three items that remains recognised after the application of all regulatory adjustments must not exceed $15 \%$ of the Common Equity Tier 1 capital, calculated after all regulatory adjustments. See Annex 2 for an example.

89. The amount of the three items that are not deducted in the calculation of Common Equity Tier 1 will be risk weighted at $250 \%$.

32 If the investment is issued out of a regulated financial entity and not included in regulatory capital in the relevant sector of the financial entity, it is not required to be deducted. 


\section{Former deductions from capital}

90. The following items, which under Basel II were deducted $50 \%$ from Tier 1 and $50 \%$ from Tier 2 (or had the option of being deducted or risk weighted), will receive a $1250 \%$ risk weight:

- $\quad$ Certain securitisation exposures;

- $\quad$ Certain equity exposures under the PD/LGD approach;

- $\quad$ Non-payment/delivery on non-DvP and non-PvP transactions; and

- $\quad$ Significant investments in commercial entities.

\section{Disclosure requirements}

91. To help improve transparency of regulatory capital and improve market discipline, banks are required to disclose the following:

- a full reconciliation of all regulatory capital elements back to the balance sheet in the audited financial statements;

- $\quad$ separate disclosure of all regulatory adjustments and the items not deducted from Common Equity Tier 1 according to paragraphs 87 and 88;

- $\quad$ a description of all limits and minima, identifying the positive and negative elements of capital to which the limits and minima apply;

- $\quad$ a description of the main features of capital instruments issued;

- $\quad$ banks which disclose ratios involving components of regulatory capital (eg "Equity Tier 1", "Core Tier 1" or "Tangible Common Equity" ratios) must accompany such disclosures with a comprehensive explanation of how these ratios are calculated.

92. Banks are also required to make available on their websites the full terms and conditions of all instruments included in regulatory capital. The Basel Committee will issue more detailed Pillar 3 disclosure requirements in 2011.

93. During the transition phase banks are required to disclose the specific components of capital, including capital instruments and regulatory adjustments that are benefiting from the transitional provisions.

\section{Transitional arrangements}

94. The transitional arrangements for implementing the new standards will help to ensure that the banking sector can meet the higher capital standards through reasonable earnings retention and capital raising, while still supporting lending to the economy. The transitional arrangements include:

(a) National implementation by member countries will begin on 1 January 2013. Member countries must translate the rules into national laws and regulations before this date. As of 1 January 2013, banks will be required to meet the following new minimum requirements in relation to risk-weighted assets (RWAs):

- $\quad 3.5 \%$ Common Equity Tier 1/RWAs;

- $\quad 4.5 \%$ Tier 1 capital/RWAs, and

- $\quad 8.0 \%$ total capital/RWAs. 
(b) The minimum Common Equity Tier 1 and Tier 1 requirements will be phased in between 1 January 2013 and 1 January 2015. On 1 January 2013, the minimum Common Equity Tier 1 requirement will rise from the current $2 \%$ level to $3.5 \%$. The Tier 1 capital requirement will rise from $4 \%$ to $4.5 \%$. On 1 January 2014 , banks will have to meet a $4 \%$ minimum Common Equity Tier 1 requirement and a Tier 1 requirement of $5.5 \%$. On 1 January 2015 , banks will have to meet the $4.5 \%$ Common Equity Tier 1 and the $6 \%$ Tier 1 requirements. The total capital requirement remains at the existing level of $8.0 \%$ and so does not need to be phased in. The difference between the total capital requirement of $8.0 \%$ and the Tier 1 requirement can be met with Tier 2 and higher forms of capital.

(c) The regulatory adjustments (ie deductions and prudential filters), including amounts above the aggregate $15 \%$ limit for significant investments in financial institutions, mortgage servicing rights, and deferred tax assets from temporary differences, would be fully deducted from Common Equity Tier 1 by 1 January 2018 .

(d) In particular, the regulatory adjustments will begin at $20 \%$ of the required adjustments to Common Equity Tier 1 on 1 January 2014, 40\% on 1 January 2015, $60 \%$ on 1 January $2016,80 \%$ on 1 January 2017, and reach $100 \%$ on 1 January 2018. During this transition period, the remainder not deducted from Common Equity Tier 1 will continue to be subject to existing national treatments. The same transition approach will apply to deductions from Additional Tier 1 and Tier 2 capital. Specifically, the regulatory adjustments to Additional Tier 1 and Tier 2 capital will begin at $20 \%$ of the required deductions on 1 January $2014,40 \%$ on 1 January $2015,60 \%$ on 1 January $2016,80 \%$ on 1 January 2017 , and reach $100 \%$ on 1 January 2018. During this transition period, the remainder not deducted from capital will continue to be subject to existing national treatments.

(e) The treatment of capital issued out of subsidiaries and held by third parties (eg minority interest) will also be phased in. Where such capital is eligible for inclusion in one of the three components of capital according to paragraphs 63 to 65 , it can be included from 1 January 2013. Where such capital is not eligible for inclusion in one of the three components of capital but is included under the existing national treatment, $20 \%$ of this amount should be excluded from the relevant component of capital on 1 January $2014,40 \%$ on 1 January $2015,60 \%$ on 1 January $2016,80 \%$ on 1 January 2017, and reach $100 \%$ on 1 January 2018.

(f) Existing public sector capital injections will be grandfathered until 1 January 2018.

(g) Capital instruments that no longer qualify as non-common equity Tier 1 capital or Tier 2 capital will be phased out beginning 1 January 2013. Fixing the base at the nominal amount of such instruments outstanding on 1 January 2013, their recognition will be capped at $90 \%$ from 1 January 2013, with the cap reducing by 10 percentage points in each subsequent year. This cap will be applied to Additional Tier 1 and Tier 2 separately and refers to the total amount of instruments outstanding that no longer meet the relevant entry criteria. To the extent an instrument is redeemed, or its recognition in capital is amortised, after 1 January 2013, the nominal amount serving as the base is not reduced. In addition, instruments with an incentive to be redeemed will be treated as follows:

- $\quad$ For an instrument that has a call and a step-up prior to 1 January 2013 (or another incentive to be redeemed), if the instrument is not called at its effective maturity date and on a forward-looking basis will meet the new criteria for inclusion in Tier 1 or Tier 2, it will continue to be recognised in that tier of capital. 
- $\quad$ For an instrument that has a call and a step-up on or after 1 January 2013 (or another incentive to be redeemed), if the instrument is not called at its effective maturity date and on a forward looking basis will meet the new criteria for inclusion in Tier 1 or Tier 2, it will continue to be recognised in that tier of capital. Prior to the effective maturity date, the instrument would be considered an "instrument that no longer qualifies as Additional Tier 1 or Tier 2" and will therefore be phased out from 1 January 2013.

- $\quad$ For an instrument that has a call and a step-up between 12 September 2010 and 1 January 2013 (or another incentive to be redeemed), if the instrument is not called at its effective maturity date and on a forward looking basis does not meet the new criteria for inclusion in Tier 1 or Tier 2, it will be fully derecognised in that tier of regulatory capital from 1 January 2013.

- $\quad$ For an instrument that has a call and a step-up on or after 1 January 2013 (or another incentive to be redeemed), if the instrument is not called at its effective maturity date and on a forward looking basis does not meet the new criteria for inclusion in Tier 1 or Tier 2, it will be derecognised in that tier of regulatory capital from the effective maturity date. Prior to the effective maturity date, the instrument would be considered an "instrument that no longer qualifies as Additional Tier 1 or Tier 2" and will therefore be phased out from 1 January 2013.

- $\quad$ For an instrument that had a call and a step-up on or prior to 12 September 2010 (or another incentive to be redeemed), if the instrument was not called at its effective maturity date and on a forward looking basis does not meet the new criteria for inclusion in Tier 1 or Tier 2, it will be considered an "instrument that no longer qualifies as Additional Tier 1 or Tier 2" and will therefore be phased out from 1 January 2013.

95. Capital instruments that do not meet the criteria for inclusion in Common Equity Tier 1 will be excluded from Common Equity Tier 1 as of 1 January 2013. However, instruments meeting the following three conditions will be phased out over the same horizon described in paragraph $94(\mathrm{~g})$ : (1) they are issued by a non-joint stock company ${ }^{33} ;(2)$ they are treated as equity under the prevailing accounting standards; and (3) they receive unlimited recognition as part of Tier 1 capital under current national banking law.

96. Only those instruments issued before 12 September 2010 qualify for the above transition arrangements.

\section{Risk Coverage}

\section{A. Counterparty credit risk}

97. In addition to raising the quality and level of the capital base, there is a need to ensure that all material risks are captured in the capital framework. Failure to capture major on- and off-balance sheet risks, as well as derivative related exposures, was a key factor that amplified the crisis. This section outlines the reforms to the counterparty credit risk framework, which become effective on 1 January 2013.

33 Non-joint stock companies were not addressed in the Basel Committee's 1998 agreement on instruments eligible for inclusion in Tier 1 capital as they do not issue voting common shares. 


\section{Revised metric to better address counterparty credit risk, credit valuation adjustments and wrong-way risk}

\section{Effective EPE with stressed parameters to address general wrong-way risk}

98. In order to implement these changes, a new paragraph 25(i) will be inserted in Section V (Internal Model Method: measuring exposure and minimum requirements), Annex 4 , of the Basel II framework and the existing paragraph 61 of Annex 4 will be revised as follows for banks with permission to use the internal models method (IMM) to calculate counterparty credit risk (CCR) regulatory capital - hereafter referred to as "IMM banks":

25(i). To determine the default risk capital charge for counterparty credit risk as defined in paragraph 105, banks must use the greater of the portfolio-level capital charge (not including the CVA charge in paragraphs 97-104) based on Effective EPE using current market data and the portfolio-level capital charge based on Effective EPE using a stress calibration. The stress calibration should be a single consistent stress calibration for the whole portfolio of counterparties. The greater of Effective EPE using current market data and the stress calibration should not be applied on a counterparty by counterparty basis, but on a total portfolio level.

61. When the Effective EPE model is calibrated using historic market data, the bank must employ current market data to compute current exposures and at least three years of historical data must be used to estimate parameters of the model. Alternatively, market implied data may be used to estimate parameters of the model. In all cases, the data must be updated quarterly or more frequently if market conditions warrant. To calculate the Effective EPE using a stress calibration, the bank must also calibrate Effective EPE using three years of data that include a period of stress to the credit default spreads of a bank's counterparties or calibrate Effective EPE using market implied data from a suitable period of stress. The following process will be used to assess the adequacy of the stress calibration:

- $\quad$ The bank must demonstrate, at least quarterly, that the stress period coincides with a period of increased CDS or other credit spreads - such as loan or corporate bond spreads - for a representative selection of the bank's counterparties with traded credit spreads. In situations where the bank does not have adequate credit spread data for a counterparty, the bank should map each counterparty to specific credit spread data based on region, internal rating and business types.

- $\quad$ The exposure model for all counterparties must use data, either historic or implied, that include the data from the stressed credit period, and must use such data in a manner consistent with the method used for the calibration of the Effective EPE model to current data.

- $\quad$ To evaluate the effectiveness of its stress calibration for Effective EPE, the bank must create several benchmark portfolios that are vulnerable to the same main risk factors to which the bank is exposed. The exposure to these benchmark portfolios shall be calculated using (a) current positions at current market prices, stressed volatilities, stressed correlations and other relevant stressed exposure model inputs from the 3-year stress period and (b) current positions at end of stress period market prices, stressed volatilities, stressed correlations and other relevant stressed exposure model inputs from the 3-year stress period. Supervisors may adjust the stress calibration if the exposures of these benchmark portfolios deviate substantially. 


\section{Capitalisation of the risk of CVA losses}

99. To implement the bond equivalent approach, the following new section VIII will be added to Annex 4 of the Basel II framework. The new paragraphs (97 to 105) are to be inserted after paragraph 96 in Annex 4.

\section{Treatment of mark-to-market counterparty risk losses (CVA capital charge)}

\section{- CVA Risk Capital Charge}

97. In addition to the default risk capital requirements for counterparty credit risk determined based on the standardised or internal ratings-based (IRB) approaches for credit risk, a bank must add a capital charge to cover the risk of mark-to-market losses on the expected counterparty risk (such losses being known as credit value adjustments, CVA) to OTC derivatives. The CVA capital charge will be calculated in the manner set forth below depending on the bank's approved method of calculating capital charges for counterparty credit risk and specific interest rate risk. A bank is not required to include in this capital charge (i) transactions with a central counterparty (CCP); and (ii) securities financing transactions (SFT), unless their supervisor determines that the bank's CVA loss exposures arising from SFT transactions are material.

A. Banks with IMM approval and Specific Interest Rate Risk VaR model ${ }^{34}$ approval for bonds: Advanced CVA risk capital charge

98. Banks with IMM approval for counterparty credit risk and approval to use the market risk internal models approach for the specific interest-rate risk of bonds must calculate this additional capital charge by modelling the impact of changes in the counterparties' credit spreads on the CVAs of all OTC derivative counterparties, together with eligible CVA hedges according to new paragraphs 102 and 103, using the bank's VaR model for bonds. This VaR model is restricted to changes in the counterparties' credit spreads and does not model the sensitivity of CVA to changes in other market factors, such as changes in the value of the reference asset, commodity, currency or interest rate of a derivative. Regardless of the accounting valuation method a bank uses for determining CVA, the CVA capital charge calculation must be based on the following formula for the CVA of each counterparty:

$C V A=\left(L G D_{M K T}\right) \cdot \sum_{i=1}^{T} \operatorname{Max}\left(0 ; \exp \left(-\frac{s_{i-1} \cdot t_{i-1}}{L G D_{M K T}}\right)-\exp \left(-\frac{s_{i} \cdot t_{i}}{L G D_{M K T}}\right)\right) \cdot\left(\frac{E E_{i-1} \cdot D_{i-1}+E E_{i} \cdot D_{i}}{2}\right)$

Where

- $\quad t_{i}$ is the time of the $i$-th revaluation time bucket, starting from $t_{0}=0$.

- $t_{T}$ is the longest contractual maturity across the netting sets with the counterparty.

34 "VaR model" refers to the internal model approach to market risk. 
- $\quad \mathrm{s}_{\mathrm{i}}$ is the credit spread of the counterparty at tenor $\mathrm{t}_{\mathrm{i}}$, used to calculate the CVA of the counterparty. Whenever the CDS spread of the counterparty is available, this must be used. Whenever such a CDS spread is not available, the bank must use a proxy spread that is appropriate based on the rating, industry and region of the counterparty.

- $\quad \mathrm{LGD}_{\mathrm{MKT}}$ is the loss given default of the counterparty and should be based on the spread of a market instrument of the counterparty (or where a counterparty instrument is not available, based on the proxy spread that is appropriate based on the rating, industry and region of the counterparty). It should be noted that this $L G D_{\mathrm{MKT}}$, which inputs into the calculation of the CVA risk capital charge, is different from the LGD that is determined for the IRB and CCR default risk charge, as this $L G D_{M K T}$ is a market assessment rather than an internal estimate.

- The first factor within the sum represents an approximation of the market implied marginal probability of a default occurring between times $t_{i-1}$ and $t_{i}$. Market implied default probability (also known as risk neutral probability) represents the market price of buying protection against a default and is in general different from the real-world likelihood of a default.

- $\quad E_{i}$ is the expected exposure to the counterparty at revaluation time $t_{i}$, as defined in paragraph 30 (regulatory expected exposure), where exposures of different netting sets for such counterparty are added, and where the longest maturity of each netting set is given by the longest contractual maturity inside the netting set. For banks using the short cut method (paragraph 41 of Annex 4) for margined trades, the paragraph 99 should be applied.

- $D_{i}$ is the default risk-free discount factor at time $t_{i}$, where $D_{0}=1$.

99. The formula in paragraph 98 must be the basis for all inputs into the bank's approved VaR model for bonds when calculating the CVA risk capital charge for a counterparty. For example, if this approved VaR model is based on full repricing, then the formula must be used directly. If the bank's approved VaR model is based on credit spread sensitivities for specific tenors, the bank must base each credit spread sensitivity on the following formula: ${ }^{35}$

$$
\text { Regulatory } \mathrm{CSO}_{i}=0.0001 \cdot t_{i} \cdot \exp \left(-\frac{s_{i} \cdot t_{i}}{L G D_{M K T}}\right) \cdot\left(\frac{E E_{i-1} \cdot D_{i-1}-E E_{i+1} \cdot D_{i+1}}{2}\right)
$$

If the bank's approved VaR model uses credit spread sensitivities to parallel shifts in credit spreads (Regulatory CS01), then the bank must use the following formula: ${ }^{36}$

35 This derivation assumes positive marginal default probabilities before and after time bucket $t_{i}$ and is valid for $\mathrm{i}<\mathrm{T}$. For the final time bucket $\mathrm{i}=\mathrm{T}$, the corresponding formula is:

$$
\text { Regulatory } \operatorname{CSO}_{T}=0.0001 \cdot t_{T} \cdot \exp \left(-\frac{s_{T} \cdot t_{T}}{L G D_{M K T}}\right) \cdot\left(\frac{E E_{T-1} \cdot D_{T-1}+E E_{T} \cdot D_{T}}{2}\right)
$$


Regulatory CS01 $=0.0001 \cdot \sum_{i=1}^{T}\left(t_{i} \cdot \exp \left(-\frac{s_{i} \cdot t_{i}}{L G D_{M K T}}\right)-t_{i-1} \cdot \exp \left(-\frac{s_{i-1} \cdot t_{i-1}}{L G D_{M K T}}\right)\right) \cdot\left(\frac{E E_{i-1} \cdot D_{i-1}+E E_{i} \cdot D_{i}}{2}\right)$

If the bank's approved VaR model uses second-order sensitivities to shifts in credit spreads (spread gamma), the gammas must be calculated based on the formula in paragraph 98.

Banks using the short cut method for collateralised OTC derivatives (paragraph 41 in Appendix 4), must compute the CVA risk capital charge according to paragraph 98, by assuming a constant EE (expected exposure) profile, where EE is set equal to the effective expected positive exposure of the shortcut method for a maturity equal to the maximum of (i) half of the longest maturity occurring in the netting set and (ii) the notional weighted average maturity of all transactions inside the netting set.

Banks with IMM approval for the majority of their businesses, but which use CEM (Current Exposure Method) or SM (Standardised Method) for certain smaller portfolios, and which have approval to use the market risk internal models approach for the specific interest rate risk of bonds, will include these non-IMM netting sets into the CVA risk capital charge, according to paragraph 98, unless the national supervisor decides that paragraph 104 should apply for these portfolios. Non-IMM netting sets are included into the advanced CVA risk capital charge by assuming a constant EE profile, where EE is set equal to the EAD as computed under CEM or SM for a maturity equal to the maximum of (i) half of the longest maturity occurring in the netting set and (ii) the notional weighted average maturity of all transactions inside the netting set. The same approach applies where the IMM model does not produce an expected exposure profile.

For exposures to certain counterparties, the bank's approved market risk VaR model may not reflect the risk of credit spread changes appropriately, because the bank's market risk $\mathrm{VaR}$ model does not appropriately reflect the specific risk of debt instruments issued by the counterparty. For such exposures, the bank is not allowed to use the advanced CVA risk charge. Instead, for these exposures the bank must determine the CVA risk charge by application of the standardised method in paragraph 104. Only exposures to counterparties for which the bank has supervisory approval for modelling the specific risk of debt instruments are to be included into the advanced CVA risk charge.

100. The CVA risk capital charge consists of both general and specific credit spread risks, including Stressed VaR but excluding IRC (incremental risk charge). The VaR figure should be determined in accordance with the quantitative standards described in paragraph 718(Lxxvi). It is thus determined as the sum of (i) the non-stressed $\mathrm{VaR}$ component and (ii) the stressed VaR component.

i. When calculating the non stressed VaR, current parameter calibrations for expected exposure must be used.

ii. When calculating the stressed VaR future counterparty EE profiles (according to the stressed exposure parameter calibrations as defined in paragraph 61 of Annex 4) must be used. The period of stress for the credit spread parameters 
should be the most severe one-year stress period contained within the threeyear stress period used for the exposure parameters. ${ }^{37}$

101. This additional CVA risk capital charge is the standalone market risk charge, calculated on the set of CVAs (as specified in paragraph 98) for all OTC derivatives counterparties, collateralised and uncollateralised, together with eligible CVA hedges. Within this standalone CVA risk capital charge, no offset against other instruments on the bank's balance sheet will be permitted (except as otherwise expressly provided herein).

102. Only hedges used for the purpose of mitigating CVA risk, and managed as such, are eligible to be included in the VaR model used to calculate the above CVA capital charge or in the standardised CVA risk capital charge set forth in paragraph 104. For example, if a credit default swap (CDS) referencing an issuer is in the bank's inventory and that issuer also happens to be an OTC counterparty but the CDS is not managed as a hedge of CVA, then such a CDS is not eligible to offset the CVA within the standalone VaR calculation of the CVA risk capital charge.

103. The only eligible hedges that can be included in the calculation of the CVA risk capital charge under paragraphs 98 or 104 are single-name CDSs, single-name contingent CDSs, other equivalent hedging instruments referencing the counterparty directly, and index CDSs. In case of index CDSs, the following restrictions apply:

- The basis between any individual counterparty spread and the spreads of index CDS hedges must be reflected in the VaR. This requirement also applies to cases where a proxy is used for the spread of a counterparty, since idiosyncratic basis still needs to be reflected in such situations. For all counterparties with no available spread, the bank must use reasonable basis time series out of a representative bucket of similar names for which a spread is available.

- If the basis is not reflected to the satisfaction of the supervisor, then the bank must reflect only $50 \%$ of the notional amount of index hedges in the $\mathrm{VaR}$.

Other types of counterparty risk hedges must not be reflected within the calculation of the CVA capital charge, and these other hedges must be treated as any other instrument in the bank's inventory for regulatory capital purposes. Tranched or nthto-default CDSs are not eligible CVA hedges. Eligible hedges that are included in the CVA capital charge must be removed from the bank's market risk capital charge calculation.

\section{B. All other banks: standardised CVA risk capital charge}

104. When a bank does not have the required approvals to use paragraph 98 to calculate a CVA capital charge for its counterparties, the bank must calculate a portfolio capital charge using the following formula:

37 Note that the three-times multiplier inherent in the calculation of a bond VaR and a stressed VaR will apply to these calculations. 


$$
K=2.33 \cdot \sqrt{h} \cdot \sqrt{\left(\sum_{i} 0.5 \cdot w_{i} \cdot\left(M_{i} \cdot E A D_{i}^{\text {total }}-M_{i}^{\text {hedge }} B_{i}\right)-\sum_{\text {ind }} w_{\text {ind }} \cdot M_{\text {ind }} \cdot B_{\text {ind }}\right)^{2}+\sum_{i} 0.75 \cdot w_{i}^{2} \cdot\left(M_{i} \cdot E A D_{i}^{\text {total }}-M_{i}^{\text {hedge }} B_{i}\right)^{2}}
$$

Where

- $\quad \mathrm{h}$ is the one-year risk horizon (in units of a year), $\mathrm{h}=1$.

- $\quad \mathrm{w}_{\mathrm{i}}$ is the weight applicable to counterparty ' $i$ '. Counterparty 'i' must be mapped to one of the seven weights $w_{i}$ based on its external rating, as shown in the table of this paragraph below. When a counterparty does not have an external rating, the bank must, subject to supervisory approval, map the internal rating of the counterparty to one of the external ratings.

- $E A D_{i}^{\text {total }}$ is the exposure at default of counterparty 'i' (summed across its netting sets), including the effect of collateral as per the existing IMM, SM or CEM rules as applicable to the calculation of counterparty risk capital charges for such counterparty by the bank. For non-IMM banks the exposure should be discounted by applying the factor $\left(1-\exp \left(-0.05^{\star} \mathrm{M}_{\mathrm{i}}\right)\right) /\left(0.05^{\star} \mathrm{M}_{\mathrm{i}}\right)$. For IMM banks, no such discount should be applied as the discount factor is already included in $\mathrm{M}_{\mathrm{i}}$.

- $\quad B_{i}$ is the notional of purchased single name CDS hedges (summed if more than one position) referencing counterparty 'i', and used to hedge CVA risk. This notional amount should be discounted by applying the factor (1-exp($\left.\left.0.05^{*} \mathrm{M}_{\mathrm{i}}^{\text {hedge }}\right)\right) /\left(0.05^{\star} \mathrm{M}_{\mathrm{i}}^{\text {hedge }}\right)$.

- $\quad B_{\text {ind }}$ is the full notional of one or more index CDS of purchased protection, used to hedge CVA risk. This notional amount should be discounted by applying the factor $\left(1-\exp \left(-0.05^{*} \mathrm{M}_{\text {ind }}\right)\right) /\left(0.05^{*} \mathrm{M}_{\text {ind }}\right)$.

- $\quad \mathrm{w}_{\text {ind }}$ is the weight applicable to index hedges. The bank must map indices to one of the seven weights $w_{i}$ based on the average spread of index 'ind'.

- $\quad \mathrm{M}_{\mathrm{i}}$ is the effective maturity of the transactions with counterparty ' $\mathrm{i}$ '. For IMMbanks, $M_{i}$ is to be calculated as per Annex 4, paragraph 38 of the Basel Accord. For non-IMM banks, $\mathrm{M}_{\mathrm{i}}$ is the notional weighted average maturity as referred to in the third bullet point of para 320. However, for this purpose, $M_{i}$ should not be capped at 5 years.

- $\quad \mathrm{Mi}^{\text {hedge }}$ is the maturity of the hedge instrument with notional $\mathrm{B}_{\mathrm{i}}$ (the quantities $\mathrm{Mi}^{\text {hedge }} \cdot \mathrm{B}_{\mathrm{i}}$ are to be summed if these are several positions).

- $\mathrm{M}^{\text {ind }}$ is the maturity of the index hedge 'ind'. In case of more than one index hedge position, it is the notional weighted average maturity.

For any counterparty that is also a constituent of an index on which a CDS is used for hedging counterparty credit risk, the notional amount attributable to that single name (as per its reference entity weight) may, with supervisory approval, be subtracted from the index CDS notional amount and treated as a single name hedge (Bi) of the individual counterparty with maturity based on the maturity of the index. 
The weights are given in this table, and are based on the external rating of the counterparty: ${ }^{38}$

\begin{tabular}{c|c}
\hline Rating & Weight $\mathbf{w}_{\mathbf{i}}$ \\
\hline AAA & $0.7 \%$ \\
\hline AA & $0.7 \%$ \\
\hline A & $0.8 \%$ \\
\hline BBB & $1.0 \%$ \\
\hline BB & $2.0 \%$ \\
\hline B & $3.0 \%$ \\
\hline CCC & $10.0 \%$ \\
\hline
\end{tabular}

105. Calculation of the aggregate CCR and CVA risk capital charges

This paragraph deals with the aggregation of the default risk capital charge and the CVA risk capital charge for potential mark-to-market losses. Note that outstanding EAD referred to in the default risk capital charges below is net of incurred CVA losses according to [new paragraph after Para 9 in Annex 4], which affects all items "i" below. In this paragraph, "IMM capital charge" refers to the default risk capital charge for CCR based on the RWAs obtained when multiplying the outstanding EAD of each counterparty under the IMM approach by the applicable credit risk weight (under the Standardised or IRB approach), and summing across counterparties. Equally, "CEM capital charge" or "SM capital charge" refer to the default risk capital charges where outstanding EADs for all counterparties in the portfolio are determined based on CEM or SM, respectively.

A. Banks with IMM approval and market-risk internal-models approval for the specific interest-rate risk of bonds

The total CCR capital charge for such a bank is determined as the sum of the following components:

i. The higher of (a) its IMM capital charge based on current parameter calibrations for EAD and (b) its IMM capital charge based on stressed parameter calibrations for EAD. For IRB banks, the risk weights applied to OTC derivative exposures should be calculated with the full maturity adjustment as a function of PD and $M$ set equal to 1 in the Basel Accord (paragraph 272), provided the bank can demonstrate to its national supervisor that its specific VaR model applied in paragraph 98 contains effects of rating migrations. If the bank cannot demonstrate this to the satisfaction of its

38 The notations follow the methodology used by one institution, Standard \& Poor's. The use of Standard \& Poor's credit ratings is an example only; those of some other approved external credit assessment institutions could be used on an equivalent basis. The ratings used throughout this document, therefore, do not express any preferences or determinations on external assessment institutions by the Committee. 
national supervisor, the full maturity adjustment function, given by the formula $(1-1.5 \times b)^{\wedge}-1 \times(1+(M-2.5) \times b)^{39}$ should apply.

ii. $\quad$ The advanced CVA risk capital charge determined pursuant to paragraphs 98 to 103.

B. Banks with IMM approval and without Specific Risk VaR approval for bonds

The total CCR capital charge for such a bank is determined as the sum of the following components:

i. The higher of (a) the IMM capital charge based on current parameter calibrations for EAD and (b) the IMM capital charge based on stressed parameter calibrations for EAD.

ii. The standardised CVA risk capital charge determined by paragraph 104 .

C. All other banks

The total CCR capital charge for such banks is determined as the sum of the following two components:

i. The sum over all counterparties of the CEM or SM based capital charge (depending on the bank's CCR approach) with EADs determined by paragraphs 91 or 69 respectively.

ii. The standardised CVA risk capital charge determined by paragraph 104 .

\section{In addition, the following paragraph will be inserted after paragraph 9 in Annex 4.}

"Outstanding EAD" for a given OTC derivative counterparty is defined as the greater of zero and the difference between the sum of EADs across all netting sets with the counterparty and the credit valuation adjustment (CVA) for that counterparty which has already been recognised by the bank as an incurred write-down (ie a CVA loss). This CVA loss is calculated without taking into account any offsetting debit valuation adjustments which have been deducted from capital under paragraph $75 .{ }^{40}$ RWAs for a given OTC derivative counterparty may be calculated as the applicable risk weight under the Standardised or IRB approach multiplied by the outstanding EAD of the counterparty. This reduction of EAD by incurred CVA losses does not apply to the determination of the CVA risk capital charge.

\section{Wrong-way risk}

100. Paragraph 57 of Annex 4 in Basel II will be revised as follows:

57. Banks must identify exposures that give rise to a greater degree of general wrong-way risk. Stress testing and scenario analyses must be designed to identify

39 Where "M" is the effective maturity and " $b$ " is the maturity adjustment as a function of the PD, as defined in paragraph 272 of the Basel Accord.

40 The incurred CVA loss deduced from exposures to determine outstanding EAD is the CVA loss gross of all debit value adjustments (DVA) which have been separately deducted from capital. To the extent DVA has not been separately deducted from a bank's capital, the incurred CVA loss used to determine outstanding EAD will be net of such DVA. 
risk factors that are positively correlated with counterparty credit worthiness. Such testing needs to address the possibility of severe shocks occurring when relationships between risk factors have changed. Banks should monitor general wrong way risk by product, by region, by industry, or by other categories that are germane to the business. Reports should be provided to senior management and the appropriate committee of the Board on a regular basis that communicate wrong way risks and the steps that are being taken to manage that risk.

\section{Implement an explicit Pillar 1 capital charge and revise Annex 4 where specific wrong-way} risk has been identified

101. In order to implement the requirement that the EAD calculation reflect a higher EAD value for counterparties where specific wrong way risk has been identified, paragraph 423 of the Basel II text and paragraphs 29 and 58 of Annex 4 will be revised as follows:

423. Each separate legal entity to which the bank is exposed must be separately rated. A bank must have policies acceptable to its supervisor regarding the treatment of individual entities in a connected group including circumstances under which the same rating may or may not be assigned to some or all related entities. Those policies must include a process for the identification of specific wrong way risk for each legal entity to which the bank is exposed. Transactions with counterparties where specific wrong way risk has been identified need to be treated differently when calculating the EAD for such exposures (see paragraph 58, Annex $4)$.

29. When using an internal model, exposure amount or EAD is calculated as the product of alpha times Effective EPE, as specified below (except for counterparties that have been identified as having explicit specific wrong way risk see paragraph 58 ):

58. A bank is exposed to "specific wrong-way risk" if future exposure to a specific counterparty is highly correlated with the counterparty's probability of default. For example, a company writing put options on its own stock creates wrongway exposures for the buyer that is specific to the counterparty. A bank must have procedures in place to identify, monitor and control cases of specific wrong way risk, beginning at the inception of a trade and continuing through the life of the trade. To calculate the CCR capital charge, the instruments for which there exists a legal connection between the counterparty and the underlying issuer, and for which specific wrong way risk has been identified, are not considered to be in the same netting set as other transactions with the counterparty. Furthermore, for single-name credit default swaps where there exists a legal connection between the counterparty and the underlying issuer, and where specific wrong way risk has been identified, $E A D$ in respect of such swap counterparty exposure equals the full expected loss in the remaining fair value of the underlying instruments assuming the underlying issuer is in liquidation. The use of the full expected loss in remaining fair value of the underlying instrument allows the bank to recognise, in respect of such swap, the market value that has been lost already and any expected recoveries. Accordingly LGD for Advanced or Foundation IRB banks must be set to $100 \%$ for such swap transactions. ${ }^{41}$ For banks using the Standardised Approach, the risk weight to use is

41 Note that the recoveries may also be possible on the underlying instrument beneath such swap. The capital requirements for such underlying exposure are to be calculated under the Accord without reduction for the swap which introduces wrong way risk. Generally this means that such underlying exposure will receive the 
that of an unsecured transaction. For equity derivatives, bond options, securities financing transactions etc. referencing a single company where there exists a legal connection between the counterparty and the underlying company, and where specific wrong way risk has been identified, EAD equals the value of the transaction under the assumption of a jump-to-default of the underlying security. Inasmuch this makes re-use of possibly existing (market risk) calculations (for IRC) that already contain an LGD assumption, the LGD must be set to $100 \%$.

\section{Asset value correlation multiplier for large financial institutions}

102. In order to implement the AVC multiplier, paragraph 272 of the Basel framework would be revised as follows:

272. Throughout this section, PD and LGD are measured as decimals, and EAD is measured as currency (eg euros), except where explicitly noted otherwise. For exposures not in default, the formula for calculating risk-weighted assets is: ${ }^{42}$

$$
\begin{aligned}
& \text { Correlation }(R)=0.12 \times(1-E X P(-50 \times P D)) /(1-E X P(-50))+ \\
& 0.24 \times[1-(1-\operatorname{EXP}(-50 \times P D)) /(1-\operatorname{EXP}(-50))] \\
& \text { Maturity adjustment }(b)=(0.11852-0.05478 \times \ln (P D))^{\wedge} 2 \\
& \text { Capital requirement }{ }^{43}(K)=\quad\left[L G D \times N\left[(1-R)^{\wedge}-0.5 \times G(P D)+(R /(1-\right.\right. \\
& \left.\left.\mathrm{R}))^{\wedge} 0.5 \times \mathrm{G}(0.999)\right]-\mathrm{PD} \times \mathrm{LGD}\right] \times(1-1.5 \times \mathrm{b})^{\wedge}-1 \times(1+ \\
& (\mathrm{M}-2.5) \times \mathrm{b})
\end{aligned}
$$

Risk-weighted assets $(\mathrm{RWA})=\mathrm{K} \times 12.5 \times \mathrm{EAD}$

The capital requirement $(K)$ for a defaulted exposure is equal to the greater of zero and the difference between its LGD (described in paragraph 468) and the bank's best estimate of expected loss (described in paragraph 471). The risk-weighted asset amount for the defaulted exposure is the product of $\mathrm{K}, 12.5$, and the EAD.

A multiplier of 1.25 is applied to the correlation parameter of all exposures to financial institutions meeting the following criteria:

- $\quad$ Regulated financial institutions whose total assets are greater than or equal to US $\$ 100$ billion. The most recent audited financial statement of the parent company and consolidated subsidiaries must be used in order to determine asset size. For the purpose of this paragraph, a regulated financial institution is defined as a parent and its subsidiaries where any substantial legal entity in

risk weight and capital treatment associated with an unsecured transaction (ie assuming such underlying exposure is an unsecured credit exposure).

42 Ln denotes the natural logarithm.

$\mathrm{N}(\mathrm{x})$ denotes the cumulative distribution function for a standard normal random variable (ie the probability that a normal random variable with mean zero and variance of one is less than or equal to $x)$. $G(z)$ denotes the inverse cumulative distribution function for a standard normal random variable (ie the value of $x$ such that $N(x)=z$ ). The normal cumulative distribution function and the inverse of the normal cumulative distribution function are, for example, available in Excel as the functions NORMSDIST and NORMSINV.

43 If this calculation results in a negative capital charge for any individual sovereign exposure, banks should apply a zero capital charge for that exposure. 
the consolidated group is supervised by a regulator that imposes prudential requirements consistent with international norms. These include, but are not limited to, prudentially regulated Insurance Companies, Broker/Dealers, Banks, Thrifts and Futures Commission Merchants;

- Unregulated financial institutions, regardless of size. Unregulated financial institutions are, for the purposes of this paragraph, legal entities whose main business includes: the management of financial assets, lending, factoring, leasing, provision of credit enhancements, securitisation, investments, financial custody, central counterparty services, proprietary trading and other financial services activities identified by supervisors.

$$
\begin{array}{r}
\text { Correlation }\left(\mathrm{R} \_\mathrm{FI}\right)=1.25 \times[0.12 \times(1-\operatorname{EXP}(-50 \times \mathrm{PD})) /(1-\operatorname{EXP}(-50))+ \\
0.24 \times[1-(1-\operatorname{EXP}(-50 \times P D)) /(1-\operatorname{EXP}(-50))]]
\end{array}
$$

\section{Collateralised counterparties and margin period of risk}

\section{Increase the margin period of risk}

103. In order to implement the increased margin periods of risk, the following new paragraphs 41 (i) and 41 (ii) will be inserted into Annex 4 of the Basel II framework:

41(i). For transactions subject to daily re-margining and mark-to-market valuation, a supervisory floor of five business days for netting sets consisting only of repo-style transactions, and 10 business days for all other netting sets is imposed on the margin period of risk used for the purpose of modelling EAD with margin agreements. In the following cases a higher supervisory floor is imposed:

- $\quad$ For all netting sets where the number of trades exceeds 5,000 at any point during a quarter, a supervisory floor of 20 business days is imposed for the margin period of risk for the following quarter.

- $\quad$ For netting sets containing one or more trades involving either illiquid collateral, or an OTC derivative that cannot be easily replaced, a supervisory floor of 20 business days is imposed for the margin period of risk. For these purposes, "Illiquid collateral" and "OTC derivatives that cannot be easily replaced" must be determined in the context of stressed market conditions and will be characterised by the absence of continuously active markets where a counterparty would, within two or fewer days, obtain multiple price quotations that would not move the market or represent a price reflecting a market discount (in the case of collateral) or premium (in the case of an OTC derivative). Examples of situations where trades are deemed illiquid for this purpose include, but are not limited to, trades that are not marked daily and trades that are subject to specific accounting treatment for valuation purposes (eg OTC derivatives or repostyle transactions referencing securities whose fair value is determined by models with inputs that are not observed in the market).

- In addition, a bank must consider whether trades or securities it holds as collateral are concentrated in a particular counterparty and if that counterparty exited the market precipitously whether the bank would be able to replace its trades.

41 (ii). If a bank has experienced more than two margin call disputes on a particular netting set over the previous two quarters that have lasted longer than the applicable margin period of risk (before consideration of this provision), then the 
bank must reflect this history appropriately by using a margin period of risk that is at least double the supervisory floor for that netting set for the subsequent two quarters.

41 (iii). For re-margining with a periodicity of $\mathrm{N}$-days, irrespective of the shortcut method or full IMM model, the margin period of risk should be at least equal to the supervisory floor, $\mathrm{F}$, plus the $\mathrm{N}$ days minus one day. That is,

$$
\text { Margin Period of Risk }=\mathrm{F}+\mathrm{N}-1
$$

Paragraph 167 of Basel II (Adjustment for different holding periods and non daily mark-tomarket or remargining) will be replaced with the following:

167. The minimum holding period for various products is summarised in the following table.

\begin{tabular}{l|l|l}
\hline \multicolumn{1}{c|}{ Transaction type } & \multicolumn{1}{c}{ Minimum holding period } & \multicolumn{1}{c}{ Condition } \\
\hline Repo-style transaction & five business days & daily remargining \\
\hline Other capital market transactions & ten business days & daily remargining \\
\hline Secured lending & twenty business days & daily revaluation \\
\hline
\end{tabular}

Where a bank has such a transaction or netting set which meets the criteria outlined in paragraphs 41 (i) or 41 (ii) of Annex 4, the minimum holding period should be the margin period of risk that would apply under those paragraphs.

Paragraph 179 of Basel II (Use of models) will be replaced with the following:

179. The quantitative and qualitative criteria for recognition of internal market risk models for repo-style transactions and other similar transactions are in principle the same as in paragraphs 718 (LXXIV) to 718 (LXXVI). With regard to the holding period, the minimum will be 5-business days for repo-style transactions, rather than the 10-business days in paragraph 718 (LXXVI) (c). For other transactions eligible for the VaR models approach, the 10-business day holding period will be retained. The minimum holding period should be adjusted upwards for market instruments where such a holding period would be inappropriate given the liquidity of the instrument concerned. At a minimum, where a bank has a repo-style or similar transaction or netting set which meets the criteria outlined in paragraphs 41 (i) or 41 (ii) of Annex 4, the minimum holding period should be the margin period of risk that would apply under those paragraphs, in combination with paragraph 41 (iii).

Revise the shortcut method for estimating Effective EPE

104. Paragraph 41 of Annex 4 in Basel II will be revised as follows:

41. Shortcut method: a bank that can model EPE without margin agreements but cannot achieve the higher level of modelling sophistication to model EPE with margin agreements can use the following method for margined counterparties 
subject to re-margining and daily mark-to-market as described in paragraph 41 (i). ${ }^{44}$ The method is a simple approximation to Effective EPE and sets Effective EPE for a margined counterparty equal to the lesser of:

a) Effective EPE without any held or posted margining collateral, plus any collateral that has been posted to the counterparty independent of the daily valuation and margining process or current exposure (ie initial margin or independent amount); or

b) An add-on that reflects the potential increase in exposure over the margin period of risk plus the larger of

i. the current exposure net of and including all collateral currently held or posted, excluding any collateral called or in dispute; or

ii. the largest net exposure including all collateral held or posted under the margin agreement that would not trigger a collateral call. This amount should reflect all applicable thresholds, minimum transfer amounts, independent amounts and initial margins under the margin agreement.

The add-on is calculated as $E[\max (\Delta M t M, 0)]$, where $E[\ldots]$ is the expectation (ie the average over scenarios) and $\Delta M t M$ is the possible change of the mark-to-market value of the transactions during the margin period of risk. Changes in the value of collateral need to be reflected using the supervisory haircut method or the internal estimates method, but no collateral payments are assumed during the margin period of risk. The margin period of risk is subject to the supervisory floor specified in paragraphs 41(i) to 41(iii). Backtesting should test whether realised (current) exposures are consistent with the shortcut method prediction over all margin periods within one year. If some of the trades in the netting set have a maturity of less than one year, and the netting set has higher risk factor sensitivities without these trades, this fact should be taken into account. If backtesting indicates that effective EPE is underestimated, the bank should take actions to make the method more conservative, eg by scaling up risk factor moves.

\section{Preclude downgrade triggers from being reflected in EAD}

105. In order to explicitly disallow downgrade triggers in $E A D$, a new paragraph 41(iv) will be inserted into Annex 4 to read as follows:

41(iv). Banks using the internal models method must not capture the effect of a reduction of EAD due to any clause in a collateral agreement that requires receipt of collateral when counterparty credit quality deteriorates.

\section{Add requirements to improve the operational performance of the collateral department}

106. To implement the requirements designed to improve the collateral department operations, two new paragraphs, 51(i) and 51(ii), will be incorporated into Annex 4 and

44 Where a bank generally uses this shortcut method to measure Effective EPE, this shortcut method may be used by a bank that is a clearing member in a CCP for its transactions with the CCP and with clients, including those client transactions that result in back-to-back trades with a CCP. 
paragraph 777(x), Part 3: The Second Pillar - Supervisory Review Process, will be revised as follows:

51(i). Banks applying the internal model method must have a collateral management unit that is responsible for calculating and making margin calls, managing margin call disputes and reporting levels of independent amounts, initial margins and variation margins accurately on a daily basis. This unit must control the integrity of the data used to make margin calls, and ensure that it is consistent and reconciled regularly with all relevant sources of data within the bank. This unit must also track the extent of reuse of collateral (both cash and non-cash) and the rights that the bank gives away to its respective counterparties for the collateral that it posts. These internal reports must indicate the categories of collateral assets that are reused, and the terms of such reuse including instrument, credit quality and maturity. The unit must also track concentration to individual collateral asset classes accepted by the banks. Senior management must allocate sufficient resources to this unit for its systems to have an appropriate level of operational performance, as measured by the timeliness and accuracy of outgoing calls and response time to incoming calls. Senior management must ensure that this unit is adequately staffed to process calls and disputes in a timely manner even under severe market crisis, and to enable the bank to limit its number of large disputes caused by trade volumes.

51(ii). The bank's collateral management unit must produce and maintain appropriate collateral management information that is reported on a regular basis to senior management. Such internal reporting should include information on the type of collateral (both cash and non-cash) received and posted, as well as the size, aging and cause for margin call disputes. This internal reporting should also reflect trends in these figures.

777(x). The bank must conduct an independent review of the CCR management system regularly through its own internal auditing process. This review must include both the activities of the business credit and trading units and of the independent CCR control unit. A review of the overall CCR management process must take place at regular intervals (ideally not less than once a year) and must specifically address, at a minimum:

- $\quad$ the adequacy of the documentation of the CCR management system and process;

- the organisation of the collateral management unit;

- $\quad$ the organisation of the CCR control unit;

- $\quad$ the integration of CCR measures into daily risk management;

- $\quad$ the approval process for risk pricing models and valuation systems used by front and back-office personnel;

- the validation of any significant change in the CCR measurement process;

- the scope of counterparty credit risks captured by the risk measurement model;

- $\quad$ the integrity of the management information system;

- $\quad$ the accuracy and completeness of CCR data;

- $\quad$ the accurate reflection of legal terms in collateral and netting agreements into exposure measurements; 
- the verification of the consistency, timeliness and reliability of data sources used to run internal models, including the independence of such data sources;

- $\quad$ the accuracy and appropriateness of volatility and correlation assumptions;

- $\quad$ the accuracy of valuation and risk transformation calculations; and

- $\quad$ the verification of the model's accuracy through frequent backtesting.

Requirements on the controls around the reuse of collateral by IMM banks

107. To implement the requirements on controls regarding the reuse of collateral, a new paragraph 51 (iii) will be included in Annex 4 as follows:

51(iii). A bank employing the internal models method must ensure that its cash management policies account simultaneously for the liquidity risks of potential incoming margin calls in the context of exchanges of variation margin or other margin types, such as initial or independent margin, under adverse market shocks, potential incoming calls for the return of excess collateral posted by counterparties, and calls resulting from a potential downgrade of its own public rating. The bank must ensure that the nature and horizon of collateral reuse is consistent with its liquidity needs and does not jeopardise its ability to post or return collateral in a timely manner.

Require banks to use supervisory haircuts when transforming non-cash OTC collateral into cash-equivalent.

108. To implement the supervisory haircuts for non-cash OTC collateral, a new paragraph 61(i) would be incorporated in Annex 4 as follows:

61(i). For a bank to recognise in its EAD calculations for OTC derivatives the effect of collateral other than cash of the same currency as the exposure itself, if it is not able to model collateral jointly with the exposure then it must use either haircuts that meet the standards of the financial collateral comprehensive method with own haircut estimates or the standard supervisory haircuts.

Requirement for banks to model non-cash collateral jointly with underlying securities for OTC Derivatives and SFTs.

109. To ensure the robustness of non-cash collateral, a new paragraph 61(ii) will be inserted in Annex 4 as follows:

61(ii). If the internal model includes the effect of collateral on changes in the market value of the netting set, the bank must model collateral other than cash of the same currency as the exposure itself jointly with the exposure in its EAD calculations for securities-financing transactions.

\section{Revise credit risk mitigation section to add a qualitative collateral management requirement}

110. To ensure that sufficient resources are devoted to the orderly operation of margin agreements for OTC derivative and SFT counterparties, and that appropriate collateral management policies are in place, a new paragraph 115(i) will be inserted into the main text and will read as follows:

115(i). Banks must ensure that sufficient resources are devoted to the orderly operation of margin agreements with OTC derivative and securities-financing 
counterparties, as measured by the timeliness and accuracy of its outgoing calls and response time to incoming calls. Banks must have collateral management policies in place to control, monitor and report:

- $\quad$ the risk to which margin agreements exposes them (such as the volatility and liquidity of the securities exchanged as collateral),

- the concentration risk to particular types of collateral,

- $\quad$ the reuse of collateral (both cash and non-cash) including the potential liquidity shortfalls resulting from the reuse of collateral received from counterparties, and

- $\quad$ the surrender of rights on collateral posted to counterparties.

Revise text to establish standard supervisory haircuts for securitisation collateral

111. To implement the supervisory haircuts for securitisation collateral, a new paragraph 145(i) will be inserted into the Basel text and paragraph 151 will be revised as follows:

145(i). Re-securitisations (as defined in the securitisation framework), irrespective of any credit ratings, are not eligible financial collateral. This prohibition applies whether the bank is using the supervisory haircuts method, the own estimates of haircuts method, the repo VaR method or the internal model method.

151. These are the standardised supervisory haircuts (assuming daily mark-tomarket, daily remargining and a 10-business day holding period), expressed as percentages:

\begin{tabular}{|c|c|c|c|c|}
\hline $\begin{array}{l}\text { Issue rating for debt } \\
\text { securities }\end{array}$ & $\begin{array}{l}\text { Residual } \\
\text { Maturity }\end{array}$ & Sovereigns & $\begin{array}{l}\text { Other } \\
\text { Issuers }\end{array}$ & $\begin{array}{l}\text { Securitisation } \\
\text { Exposures }\end{array}$ \\
\hline \multirow{3}{*}{ AAA to $A A-/ A-1$} & $<1$ year & 0.5 & 1 & 2 \\
\hline & $>1$ year $<5$ years & 2 & 4 & 8 \\
\hline & $>5$ years & 4 & 8 & 16 \\
\hline \multirow{3}{*}{$\begin{array}{l}A+\text { to } B B B-/ \\
A-2 / A-3 / P-3 \text { and } \\
\text { unrated bank securities }\end{array}$} & $<1$ year & 1 & 2 & 4 \\
\hline & $>1$ year $<5$ years & 3 & 6 & 12 \\
\hline & $>5$ years & 6 & 12 & 24 \\
\hline $\mathrm{BB}+$ to $\mathrm{BB}-$ & All & 15 & Not Eligible & Not Eligible \\
\hline main index equities & \multicolumn{4}{|c|}{15} \\
\hline other equities & \multicolumn{4}{|c|}{25} \\
\hline UCITS/mutual funds & \multicolumn{4}{|c|}{$\begin{array}{l}\text { Highest haircut applicable to any security in } \\
\text { fund }\end{array}$} \\
\hline Cash in the same currency & \multicolumn{4}{|c|}{0} \\
\hline
\end{tabular}

(The footnotes associated with the table are not included. However, securitisation exposures would be defined as those exposures that meet the definition set forth in the securitisation framework.)

\section{Treatment of highly leveraged counterparties}

112. The Committee believes it is appropriate to add a qualitative requirement indicating that the PD estimates for highly leveraged counterparties should reflect the performance of their assets based on a stressed period and, thus, is introducing a new paragraph after 415 of the framework to read as follows: 
415(i). PD estimates for borrowers that are highly leveraged or for borrowers whose assets are predominantly traded assets must reflect the performance of the underlying assets based on periods of stressed volatilities.

\section{Central counterparties}

113. The Committee acknowledges the ongoing work of the Committee on Payment and Settlement Systems (CPSS) and the International Organization of Securities Commissions (IOSCO) to review the 2004 CPSS-IOSCO Recommendations for Central Counterparties. Subject to the completion of the revision of the CPSS-IOSCO standards, which cover, among other things, the risk management of a CCP, the Committee will apply a regulatory capital treatment for exposures to CCPs based in part on the compliance of the CCP with the enhanced CPSS-IOSCO standards. The Committee separately will issue for public consultation a set of rules relating to the capitalisation of bank exposures to central counterparties (CCPs). This set of standards will be finalised during 2011, once such consultation and an impact study are complete and after CPSS-IOSCO has completed the update of its standards applicable to CCPs. The Committee intends for these standards to come into effect at the same time as other counterparty credit risk reforms.

\section{Enhanced counterparty credit risk management requirements}

114. Paragraph 36 of Annex 4 will be revised as follows to increase the robustness of banks' own estimates of alpha.

36. To this end, banks must ensure that the numerator and denominator of alpha are computed in a consistent fashion with respect to the modelling methodology, parameter specifications and portfolio composition. The approach used must be based on the bank's internal economic capital approach, be welldocumented and be subject to independent validation. In addition, banks must review their estimates on at least a quarterly basis, and more frequently when the composition of the portfolio varies over time. Banks must assess the model risk and supervisors should be alert to the significant variation in estimates of alpha that arises from the possibility for mis-specification in the models used for the numerator, especially where convexity is present.

\section{Stress testing}

115. The qualitative requirements set forth in Annex 4 for stress testing that banks must perform when using the internal model method have been expanded and made more explicit. More specifically, the existing paragraph 56, Annex 4, of the Basel II text will be replaced with the following:

56. Banks must have a comprehensive stress testing program for counterparty credit risk. The stress testing program must include the following elements:

- Banks must ensure complete trade capture and exposure aggregation across all forms of counterparty credit risk (not just OTC derivatives) at the counterparty-specific level in a sufficient time frame to conduct regular stress testing.

- $\quad$ For all counterparties, banks should produce, at least monthly, exposure stress testing of principal market risk factors (eg interest rates, FX, equities, credit spreads, and commodity prices) in order to proactively identify, and when necessary, reduce outsized concentrations to specific directional sensitivities. 
- $\quad$ Banks should apply multifactor stress testing scenarios and assess material non-directional risks (ie yield curve exposure, basis risks, etc) at least quarterly. Multiple-factor stress tests should, at a minimum, aim to address scenarios in which a) severe economic or market events have occurred; b) broad market liquidity has decreased significantly; and c) the market impact of liquidating positions of a large financial intermediary. These stress tests may be part of bank-wide stress testing.

- $\quad$ Stressed market movements have an impact not only on counterparty exposures, but also on the credit quality of counterparties. At least quarterly, banks should conduct stress testing applying stressed conditions to the joint movement of exposures and counterparty creditworthiness.

- $\quad$ Exposure stress testing (including single factor, multifactor and material non-directional risks) and joint stressing of exposure and creditworthiness should be performed at the counterparty-specific, counterparty group (eg industry and region), and aggregate bank-wide CCR levels.

- $\quad$ Stress tests results should be integrated into regular reporting to senior management. The analysis should capture the largest counterparty-level impacts across the portfolio, material concentrations within segments of the portfolio (within the same industry or region), and relevant portfolio and counterparty specific trends.

- $\quad$ The severity of factor shocks should be consistent with the purpose of the stress test. When evaluating solvency under stress, factor shocks should be severe enough to capture historical extreme market environments and/or extreme but plausible stressed market conditions. The impact of such shocks on capital resources should be evaluated, as well as the impact on capital requirements and earnings. For the purpose of day-to-day portfolio monitoring, hedging, and management of concentrations, banks should also consider scenarios of lesser severity and higher probability.

- Banks should consider reverse stress tests to identify extreme, but plausible, scenarios that could result in significant adverse outcomes.

- $\quad$ Senior management must take a lead role in the integration of stress testing into the risk management framework and risk culture of the bank and ensure that the results are meaningful and proactively used to manage counterparty credit risk. At a minimum, the results of stress testing for significant exposures should be compared to guidelines that express the bank's risk appetite and elevated for discussion and action when excessive or concentrated risks are present.

\section{Model validation and backtesting}

116. On model validation, the following paragraph (currently in paragraph 42) will be moved after paragraph 40 of Annex 4:

40bis. An EPE model must also include transaction-specific information in order to capture the effects of margining. It must take into account both the current amount of margin and margin that would be passed between counterparties in the future. Such a model must account for the nature of margin agreements (unilateral or bilateral), the frequency of margin calls, the margin period of risk, the thresholds of unmargined exposure the bank is willing to accept, and the minimum transfer amount. Such a model must either model the mark-to-market change in the value of collateral posted or apply this Framework's rules for collateral. 
117. The current Basel II requirements for backtesting will be replaced with the following:

42. It is important that supervisory authorities are able to assure themselves that banks using models have counterparty credit risk management systems that are conceptually sound and implemented with integrity. Accordingly the supervisory authority will specify a number of qualitative criteria that banks would have to meet before they are permitted to use a models-based approach. The extent to which banks meet the qualitative criteria may influence the level at which supervisory authorities will set the multiplication factor referred to in paragraph 32 (Alpha) above. Only those banks in full compliance with the qualitative criteria will be eligible for application of the minimum multiplication factor. The qualitative criteria include:

- $\quad$ The bank must conduct a regular programme of backtesting, ie an ex-post comparison of the risk measures ${ }^{45}$ generated by the model against realised risk measures, as well as comparing hypothetical changes based on static positions with realised measures.

- $\quad$ The bank must carry out an initial validation and an on-going periodic review of its IMM model and the risk measures generated by it. The validation and review must be independent of the model developers.

- $\quad$ The board of directors and senior management should be actively involved in the risk control process and must regard credit and counterparty credit risk control as an essential aspect of the business to which significant resources need to be devoted. In this regard, the daily reports prepared by the independent risk control unit must be reviewed by a level of management with sufficient seniority and authority to enforce both reductions of positions taken by individual traders and reductions in the bank's overall risk exposure.

- $\quad$ The bank's internal risk measurement exposure model must be closely integrated into the day-to-day risk management process of the bank. Its output should accordingly be an integral part of the process of planning, monitoring and controlling the bank's counterparty credit risk profile.

- $\quad$ The risk measurement system should be used in conjunction with internal trading and exposure limits. In this regard, exposure limits should be related to the bank's risk measurement model in a manner that is consistent over time and that is well understood by traders, the credit function and senior management.

- Banks should have a routine in place for ensuring compliance with a documented set of internal policies, controls and procedures concerning the operation of the risk measurement system. The bank's risk measurement system must be well documented, for example, through a risk management manual that describes the basic principles of the risk management system and that provides an explanation of the empirical techniques used to measure counterparty credit risk.

- $\quad$ An independent review of the risk measurement system should be carried out regularly in the bank's own internal auditing process. This review should

45 "Risk measures" refers not only to Effective EPE, the risk measure used to derive regulatory capital, but also to the other risk measures used in the calculation of Effective EPE such as the exposure distribution at a series of future dates, the positive exposure distribution at a series of future dates, the market risk factors used to derive those exposures and the values of the constituent trades of a portfolio. 
include both the activities of the business trading units and of the independent risk control unit. A review of the overall risk management process should take place at regular intervals (ideally no less than once a year) and should specifically address, at a minimum:

- The adequacy of the documentation of the risk management system and process;

- The organisation of the risk control unit;

- The integration of counterparty credit risk measures into daily risk management;

- $\quad$ The approval process for counterparty credit risk models used in the calculation of counterparty credit risk used by front office and back office personnel;

- The validation of any significant change in the risk measurement process;

- The scope of counterparty credit risks captured by the risk measurement model;

- The integrity of the management information system;

- $\quad$ The accuracy and completeness of position data;

- The verification of the consistency, timeliness and reliability of data sources used to run internal models, including the independence of such data sources;

- The accuracy and appropriateness of volatility and correlation assumptions;

- $\quad$ The accuracy of valuation and risk transformation calculations; and

- The verification of the model's accuracy as described below in paragraphs 43-46.

- The on-going validation of counterparty credit risk models, including backtesting, must be reviewed periodically by a level of management with sufficient authority to decide the course of action that will be taken to address weaknesses in the models.

43. Banks must document the process for initial and on-going validation of their IMM model to a level of detail that would enable a third party to recreate the analysis. Banks must also document the calculation of the risk measures generated by the models to a level of detail that would allow a third party to re-create the risk measures. This documentation must set out the frequency with which backtesting analysis and any other on-going validation will be conducted, how the validation is conducted with respect to dataflows and portfolios and the analyses that are used.

44. Banks must define criteria with which to assess their EPE models and the models that input into the calculation of EPE and have a written policy in place that describes the process by which unacceptable performance will be determined and remedied. 
45. Banks must define how representative counterparty portfolios are constructed for the purposes of validating an EPE model and its risk measures.

46. When validating EPE models and its risk measures that produce forecast distributions, validation must assess more than a single statistic of the model distribution.

46(i) As part of the initial and on-going validation of an IMM model and its risk measures, the following requirements must be met:

- $\quad$ A bank must carry out backtesting using historical data on movements in market risk factors prior to supervisory approval. Backtesting must consider a number of distinct prediction time horizons out to at least one year, over a range of various start (initialisation) dates and covering a wide range of market conditions.

- $\quad$ Banks must backtest the performance of their EPE model and the model's relevant risk measures as well as the market risk factor predictions that support EPE. For collateralised trades, the prediction time horizons considered must include those reflecting typical margin periods of risk applied in collateralised/margined trading, and must include long time horizons of at least 1 year.

- $\quad$ The pricing models used to calculate counterparty credit risk exposure for a given scenario of future shocks to market risk factors must be tested as part of the initial and on-going model validation process. These pricing models may be different from those used to calculate Market Risk over a short horizon. Pricing models for options must account for the nonlinearity of option value with respect to market risk factors.

- $\quad$ An EPE model must capture transaction specific information in order to aggregate exposures at the level of the netting set. Banks must verify that transactions are assigned to the appropriate netting set within the model.

- $\quad$ Static, historical backtesting on representative counterparty portfolios must be a part of the validation process. At regular intervals as directed by its supervisor, a bank must conduct such backtesting on a number of representative counterparty portfolios. The representative portfolios must be chosen based on their sensitivity to the material risk factors and correlations to which the bank is exposed. In addition, IMM banks need to conduct backtesting that is designed to test the key assumptions of the EPE model and the relevant risk measures, eg the modelled relationship between tenors of the same risk factor, and the modelled relationships between risk factors.

- $\quad$ Significant differences between realised exposures and the forecast distribution could indicate a problem with the model or the underlying data that the supervisor would require the bank to correct. Under such circumstances, supervisors may require additional capital to be held while the problem is being solved.

- $\quad$ The performance of EPE models and its risk measures must be subject to good backtesting practice. The backtesting programme must be capable of identifying poor performance in an EPE model's risk measures. 
- $\quad$ Banks must validate their EPE models and all relevant risk measures out to time horizons commensurate with the maturity of trades for which exposure is calculated using an internal modelling method.

- $\quad$ The pricing models used to calculate counterparty exposure must be regularly tested against appropriate independent benchmarks as part of the on-going model validation process.

- $\quad$ The on-going validation of a bank's EPE model and the relevant risk measures include an assessment of recent performance.

- $\quad$ The frequency with which the parameters of an EPE model are updated needs to be assessed as part of the validation process.

- $\quad$ Under the IMM, a measure that is more conservative than the metric used to calculate regulatory EAD for every counterparty, may be used in place of alpha times Effective EPE with the prior approval of the supervisor. The degree of relative conservatism will be assessed upon initial supervisory approval and at the regular supervisory reviews of the EPE models. The bank must validate the conservatism regularly.

- The on-going assessment of model performance needs to cover all counterparties for which the models are used.

- $\quad$ The validation of IMM models must assess whether or not the bank level and netting set exposure calculations of EPE are appropriate.

49(i). The bank must have an independent risk control unit that is responsible for the design and implementation of the bank's counterparty credit risk management system. The unit should produce and analyse daily reports on the output of the bank's risk measurement model, including an evaluation of the relationship between measures of counterparty credit exposure and trading limits. The unit must be independent from the business trading units and should report directly to senior management of the bank.

\section{B. Addressing reliance on external credit ratings and minimising cliff effects}

\section{Standardised inferred rating treatment for long-term exposures}

118. Para. 99 of the Basel II text would be modified as follows:

99. Where a bank invests in a particular issue that has an issue-specific assessment, the risk weight of the claim will be based on this assessment. Where the bank's claim is not an investment in a specific assessed issue, the following general principles apply.

- In circumstances where the borrower has a specific assessment for an issued debt - but the bank's claim is not an investment in this particular debt - a high quality credit assessment (one which maps into a risk weight lower than that which applies to an unrated claim) on that specific debt may only be applied to the bank's unassessed claim if this claim ranks pari passu or senior to the claim with an assessment in all respects. If not, the credit assessment cannot be used and the unassessed claim will receive the risk weight for unrated claims. 
In circumstances where the borrower has an issuer assessment, this assessment typically applies to senior unsecured claims on that issuer. Consequently, only senior claims on that issuer will benefit from a high quality issuer assessment. Other unassessed claims of a highly assessed issuer will be treated as unrated. If either the issuer or a single issue has a low quality assessment (mapping into a risk weight equal to or higher than that which applies to unrated claims), an unassessed claim on the same counterparty that ranks pari passu or is subordinated to either the senior unsecured issuer assessment or the exposure assessment will be assigned the same risk weight as is applicable to the low quality assessment.

\section{Incentive to avoid getting exposures rated}

119. Para. 733 of the Basel II text will read as follows:

733. Credit risk: Banks should have methodologies that enable them to assess the credit risk involved in exposures to individual borrowers or counterparties as well as at the portfolio level. Banks should assess exposures, regardless of whether they are rated or unrated, and determine whether the risk weights applied to such exposures, under the Standardised Approach, are appropriate for their inherent risk. In those instances where a bank determines that the inherent risk of such an exposure, particularly if it is unrated, is significantly higher than that implied by the risk weight to which it is assigned, the bank should consider the higher degree of credit risk in the evaluation of its overall capital adequacy. For more sophisticated banks, the credit review assessment of capital adequacy, at a minimum, should cover four areas: risk rating systems, portfolio analysis/aggregation, securitisation/complex credit derivatives, and large exposures and risk concentrations.

\section{Incorporation of IOSCO's Code of Conduct Fundamentals for Credit Rating Agencies}

120. Paragraph 91 and 565(b) of the Basel II text will read as follows (paragraph 90 does not need additional changes):

\section{The recognition process}

90. National supervisors are responsible for determining on a continuous basis whether an external credit assessment institution (ECAI) meets the criteria listed in the paragraph below. National supervisors should refer to the IOSCO Code of Conduct Fundamentals for Credit Rating Agencies when determining ECAI eligibility. The assessments of ECAls may be recognised on a limited basis, e.g. by type of claims or by jurisdiction. The supervisory process for recognising ECAls should be made public to avoid unnecessary barriers to entry.

2. Eligibility criteria

91. An ECAI must satisfy each of the following six criteria.

- $\quad$ Objectivity: no change suggested

- Independence: no change suggested

- International access/Transparency: The individual assessments, the key elements underlining the assessments and whether the issuer participated in the assessment process_should be publicly available on a non-selective 
basis, unless they are private assessments. In addition, the general procedures, methodologies and assumptions for arriving at assessments used by the ECAI should be publicly available.

- Disclosure: An ECAl should disclose the following information: its code of conduct; the general nature of its compensation arrangements with assessed entities; its assessment methodologies, including the definition of default, the time horizon, and the meaning of each rating; the actual default rates experienced in each assessment category; and the transitions of the assessments, e.g. the likelihood of AA ratings becoming $A$ over time.

- $\quad$ Resources: no change suggested

- $\quad$ Credibility: no change suggested

3. Operational requirements for use of external credit assessments

565. The following operational criteria concerning the use of external credit assessments apply in the standardised and IRB approaches of the securitisation framework:

(a) no change

(b) The external credit assessments must be from an eligible ECAI as recognised by the bank's national supervisor in accordance with paragraphs 90 to 108 with the following exception. In contrast with bullet three of paragraph 91, an eligible credit assessment, procedures, methodologies, assumptions, and the key elements underlining the assessments must be publicly available, on a non-selective basis and free of charge. ${ }^{46}$ In other words, a rating must be published in an accessible form and included in the ECAl's transition matrix. Also, loss and cashflow analysis as well as sensitivity of ratings to changes in the underlying ratings assumptions should be publicly available. Consequently, ratings that are made available only to the parties to a transaction do not satisfy this requirement.

(c) to (f) no change

\section{4. "Cliff effects" arising from guarantees and credit derivatives - Credit risk mitigation (CRM)}

Standardised Approach - Range of eligible guarantors (counter-guarantors)/protection providers

195. Credit protection given by the following entities will be recognised:

- $\quad$ sovereign entities, PSEs, banks, and securities firms with a lower risk weight than the counterparty.

- $\quad$ other entities that are externally rated except when credit protection is provided to a securitisation exposure. This would include credit protection provided by parent, subsidiary and affiliate companies when they have a lower risk weight than the obligor.

46 Where the eligible credit assessment is not provided free of charge the ECAl should provide an adequate justification, within their own publicly available Code of Conduct, in accordance with the 'comply or explain' nature of the IOSCO Code of Conduct Fundamentals for Credit Rating Agencies. 
- when credit protection is provided to a securitisation exposure, other entities that currently are externally rated BBB- or better and that were externally rated A- or better at the time the credit protection was provided. This would include credit protection provided by parent, subsidiary and affiliate companies when they have a lower risk weight than the obligor.

\section{Recognition under the Foundation IRB approach}

302. For banks using the foundation approach for LGD, the approach to guarantees and credit derivatives closely follows the treatment under the standardised approach as specified in paragraphs 189 to 201. The range of eligible guarantors is the same as under the standardised approach except that companies that are internally rated may also be recognised under the foundation approach. To receive recognition, the requirements outlined in paragraphs 189 to 194 must be met.

\section{Unsolicited ratings and recognition of ECAls}

121. Paragraph 94 and 108 of the Basel II text will be modified as follows:

94. Banks must use the chosen ECAls and their ratings consistently for each type of claim, for both risk weighting and risk management purposes. Banks will not be allowed to "cherry-pick" the assessments provided by different ECAls and to arbitrarily change the use of ECAls.

108. As a general rule, banks should use solicited ratings from eligible ECAls. National supervisory authorities may, however, allow banks to use unsolicited ratings in the same way as solicited ratings if they are satisfied that the credit assessments of unsolicited ratings are not inferior in quality to the general quality of solicited ratings. However, there may be the potential for ECAls to use unsolicited ratings to put pressure on entities to obtain solicited ratings. Such behaviour, when identified, should cause supervisors to consider whether to continue recognising such ECAls as eligible for capital adequacy purposes.

\section{Capital conservation buffer}

122. This section outlines the operation of the capital conservation buffer, which is designed to ensure that banks build up capital buffers outside periods of stress which can be drawn down as losses are incurred. The requirement is based on simple capital conservation rules designed to avoid breaches of minimum capital requirements.

\section{A. Capital conservation best practice}

123. Outside of periods of stress, banks should hold buffers of capital above the regulatory minimum.

124. When buffers have been drawn down, one way banks should look to rebuild them is through reducing discretionary distributions of earnings. This could include reducing dividend payments, share-backs and staff bonus payments. Banks may also choose to raise new capital from the private sector as an alternative to conserving internally generated capital. 
The balance between these options should be discussed with supervisors as part of the capital planning process.

125. It is clear that greater efforts should be made to rebuild buffers the more they have been depleted. Therefore, in the absence of raising capital in the private sector, the share of earnings retained by banks for the purpose of rebuilding their capital buffers should increase the nearer their actual capital levels are to the minimum capital requirement.

126. It is not acceptable for banks which have depleted their capital buffers to use future predictions of recovery as justification for maintaining generous distributions to shareholders, other capital providers and employees. These stakeholders, rather than depositors, must bear the risk that recovery will not be forthcoming.

127. It is also not acceptable for banks which have depleted their capital buffers to try and use the distribution of capital as a way to signal their financial strength. Not only is this irresponsible from the perspective of an individual bank, putting shareholders interests above depositors, it may also encourage other banks to follow suit. As a consequence, banks in aggregate can end up increasing distributions at the exact point in time when they should be conserving earnings.

128. The framework reduces the discretion of banks which have depleted their capital buffers to further reduce them through generous distributions of earnings. In doing so, the framework will strengthen their ability to withstand adverse environments. Implementation of the framework through internationally agreed capital conservation rules will help increase sector resilience both going into a downturn, and provide the mechanism for rebuilding capital during the early stages of economic recovery. Retaining a greater proportion of earnings during a downturn will help ensure that capital remains available to support the ongoing business operations of banks through the period of stress. In this way the framework should help reduce procyclicality.

\section{B. The framework}

129. A capital conservation buffer of $2.5 \%$, comprised of Common Equity Tier 1 , is established above the regulatory minimum capital requirement. ${ }^{47}$ Capital distribution constraints will be imposed on a bank when capital levels fall within this range. Banks will be able to conduct business as normal when their capital levels fall into the conservation range as they experience losses. The constraints imposed only relate to distributions, not the operation of the bank.

130. The distribution constraints imposed on banks when their capital levels fall into the range increase as the banks' capital levels approach the minimum requirements. By design, the constraints imposed on banks with capital levels at the top of the range would be minimal. This reflects an expectation that banks' capital levels will from time to time fall into this range. The Basel Committee does not wish to impose constraints for entering the range that would be so restrictive as to result in the range being viewed as establishing a new minimum capital requirement.

47 Common Equity Tier 1 must first be used to meet the minimum capital requirements (including the $6 \%$ Tier 1 and $8 \%$ Total capital requirements if necessary), before the remainder can contribute to the capital conservation buffer. 
131. The table below shows the minimum capital conservation ratios a bank must meet at various levels of the Common Equity Tier 1 (CET1) capital ratios. For example, a bank with a CET1 capital ratio in the range of $5.125 \%$ to $5.75 \%$ is required to conserve $80 \%$ of its earnings in the subsequent financial year (ie payout no more than $20 \%$ in terms of dividends, share buybacks and discretionary bonus payments). If the bank wants to make payments in excess of the constraints imposed by this regime, it would have the option of raising capital in the private sector equal to the amount above the constraint which it wishes to distribute. This would be discussed with the bank's supervisor as part of the capital planning process. The Common Equity Tier 1 ratio includes amounts used to meet the $4.5 \%$ minimum Common Equity Tier 1 requirement, but excludes any additional Common Equity Tier 1 needed to meet the $6 \%$ Tier 1 and $8 \%$ Total Capital requirements. For example, a bank with $8 \%$ CET1 and no Additional Tier 1 or Tier 2 capital would meet all minimum capital requirements, but would have a zero conservation buffer and therefore by subject to the $100 \%$ constraint on capital distributions.

Individual bank minimum capital conservation standards

\begin{tabular}{c|c}
\hline Common Equity Tier 1 Ratio & $\begin{array}{c}\text { Minimum Capital Conservation Ratios } \\
\text { expressed as a percentage of earnings) }\end{array}$ \\
\hline $4.5 \%-5.125 \%$ & $100 \%$ \\
\hline$>5.125 \%-5.75 \%$ & $80 \%$ \\
\hline$>5.75 \%-6.375 \%$ & $60 \%$ \\
\hline$>6.375 \%-7.0 \%$ & $40 \%$ \\
\hline$>7.0 \%$ & $0 \%$ \\
\hline
\end{tabular}

132. Set out below are a number of other key aspects of the requirements:

(a) Elements subject to the restriction on distributions: Items considered to be distributions include dividends and share buybacks, discretionary payments on other Tier 1 capital instruments and discretionary bonus payments to staff. Payments that do not result in a depletion of Common Equity Tier 1, which may for example include certain scrip dividends, are not considered distributions.

(b) Definition of earnings: Earnings are defined as distributable profits calculated prior to the deduction of elements subject to the restriction on distributions. Earnings are calculated after the tax which would have been reported had none of the distributable items been paid. As such, any tax impact of making such distributions are reversed out. Where a bank does not have positive earnings and has a Common Equity Tier 1 ratio less than $7 \%$, it would be restricted from making positive net distributions.

(c) Solo or consolidated application: The framework should be applied at the consolidated level, ie restrictions would be imposed on distributions out of the consolidated group. National supervisors would have the option of applying the regime at the solo level to conserve resources in specific parts of the group.

(d) Additional supervisory discretion: Although the buffer must be capable of being drawn down, banks should not choose in normal times to operate in the buffer range simply to compete with other banks and win market share. To ensure that this does not happen, supervisors have the additional discretion to impose time limits on banks operating within the buffer range on a case-by-case basis. In any case, 
supervisors should ensure that the capital plans of banks seek to rebuild buffers over an appropriate timeframe.

\section{Transitional arrangements}

133. The capital conservation buffer will be phased in between 1 January 2016 and year end 2018 becoming fully effective on 1 January 2019. It will begin at $0.625 \%$ of RWAs on 1 January 2016 and increase each subsequent year by an additional 0.625 percentage points, to reach its final level of $2.5 \%$ of RWAs on 1 January 2019. Countries that experience excessive credit growth should consider accelerating the build up of the capital conservation buffer and the countercyclical buffer. National authorities have the discretion to impose shorter transition periods and should do so where appropriate.

134. Banks that already meet the minimum ratio requirement during the transition period but remain below the $7 \%$ Common Equity Tier 1 target (minimum plus conservation buffer) should maintain prudent earnings retention policies with a view to meeting the conservation buffer as soon as reasonably possible.

135. The division of the buffer into quartiles that determine the minimum capital conservation ratios will begin on 1 January 2016. These quartiles will expand as the capital conservation buffer is phased in and will take into account any countercyclical buffer in effect during this period.

\section{Countercyclical buffer}

\section{A. Introduction}

136. Losses incurred in the banking sector can be extremely large when a downturn is preceded by a period of excess credit growth. These losses can destabilise the banking sector and spark a vicious circle, whereby problems in the financial system can contribute to a downturn in the real economy that then feeds back on to the banking sector. These interactions highlight the particular importance of the banking sector building up additional capital defences in periods where the risks of system-wide stress are growing markedly.

137. The countercyclical buffer aims to ensure that banking sector capital requirements take account of the macro-financial environment in which banks operate. It will be deployed by national jurisdictions when excess aggregate credit growth is judged to be associated with a build-up of system-wide risk to ensure the banking system has a buffer of capital to protect it against future potential losses. This focus on excess aggregate credit growth means that jurisdictions are likely to only need to deploy the buffer on an infrequent basis. The buffer for internationally-active banks will be a weighted average of the buffers deployed across all the jurisdictions to which it has credit exposures. This means that they will likely find themselves subject to a small buffer on a more frequent basis, since credit cycles are not always highly correlated across jurisdictions.

138. The countercyclical buffer regime consists of the following elements:

(a) National authorities will monitor credit growth and other indicators that may signal a build up of system-wide risk and make assessments of whether credit growth is excessive and is leading to the build up of system-wide risk. Based on this assessment they will put in place a countercyclical buffer requirement when 
circumstances warrant. This requirement will be released when system-wide risk crystallises or dissipates.

(b) Internationally active banks will look at the geographic location of their private sector credit exposures and calculate their bank specific countercyclical capital buffer requirement as a weighted average of the requirements that are being applied in jurisdictions to which they have credit exposures.

(c) The countercyclical buffer requirement to which a bank is subject will extend the size of the capital conservation buffer. Banks will be subject to restrictions on distributions if they do not meet the requirement.

\section{B. National countercyclical buffer requirements}

139. Each Basel Committee member jurisdiction will identify an authority with the responsibility to make decisions on the size of the countercyclical capital buffer. If the relevant national authority judges a period of excess credit growth to be leading to the build up of system-wide risk, they will consider, together with any other macroprudential tools at their disposal, putting in place a countercyclical buffer requirement. This will vary between zero and $2.5 \%$ of risk weighted assets, depending on their judgement as to the extent of the build up of system-wide risk. ${ }^{48}$

140. The document entitled Guidance for national authorities operating the countercyclical capital buffer, sets out the principles that national authorities have agreed to follow in making buffer decisions. This document provides information that should help banks to understand and anticipate the buffer decisions made by national authorities in the jurisdictions to which they have credit exposures.

141. To give banks time to adjust to a buffer level, a jurisdiction will pre-announce its decision to raise the level of the countercyclical buffer by up to 12 months. ${ }^{49}$ Decisions by a jurisdiction to decrease the level of the countercyclical buffer will take effect immediately. The pre-announced buffer decisions and the actual buffers in place for all Committee member jurisdictions will be published on the BIS website.

\section{Bank specific countercyclical buffer}

142. Banks will be subject to a countercyclical buffer that varies between zero and $2.5 \%$ to total risk weighted assets. ${ }^{50}$ The buffer that will apply to each bank will reflect the geographic composition of its portfolio of credit exposures. Banks must meet this buffer with

48 National authorities can implement a range of additional macroprudential tools, including a buffer in excess of $2.5 \%$ for banks in their jurisdiction, if this is deemed appropriate in their national context. However, the international reciprocity provisions set out in this regime treat the maximum countercyclical buffer as $2.5 \%$.

49 Banks outside of this jurisdiction with credit exposures to counterparties in this jurisdiction will also be subject to the increased buffer level after the pre-announcement period in respect of these exposures. However, in cases where the pre-announcement period of a jurisdiction is shorter than 12 months, the home authority of such banks should seek to match the preannouncement period where practical, or as soon as possible (subject to a maximum preannouncement period of 12 months), before the new buffer level comes into effect.

50 As with the capital conservation buffer, the framework will be applied at the consolidated level. In addition, national supervisors may apply the regime at the solo level to conserve resources in specific parts of the group. 
Common Equity Tier 1 or other fully loss absorbing capital ${ }^{51}$ or be subject to the restrictions on distributions set out in the next Section.

143. Internationally active banks will look at the geographic location of their private sector credit exposures (including non-bank financial sector exposures) and calculate their countercyclical capital buffer requirement as a weighted average of the buffers that are being applied in jurisdictions to which they have an exposure. Credit exposures in this case include all private sector credit exposures that attract a credit risk capital charge or the risk weighted equivalent trading book capital charges for specific risk, IRC and securitisation.

144. The weighting applied to the buffer in place in each jurisdiction will be the bank's total credit risk charge that relates to private sector credit exposures in that jurisdiction ${ }^{52}$, divided by the bank's total credit risk charge that relates to private sector credit exposures across all jurisdictions.

145. For the VaR for specific risk, the incremental risk charge and the comprehensive risk measurement charge, banks should work with their supervisors to develop an approach that would translate these charges into individual instrument risk weights that would then be allocated to the geographic location of the specific counterparties that make up the charge. However, it may not always be possible to break down the charges in this way due to the charges being calculated on a portfolio by portfolio basis. In such cases, the charge for the relevant portfolio should be allocated to the geographic regions of the constituents of the portfolio by calculating the proportion of the portfolio's total exposure at default (EAD) that is due to the EAD resulting from counterparties in each geographic region.

\section{Extension of the capital conservation buffer}

146. The countercyclical buffer requirement to which a bank is subject is implemented through an extension of the capital conservation buffer described in section III.

147. The table below shows the minimum capital conservation ratios a bank must meet at various levels of the Common Equity Tier 1 capital ratio. ${ }^{53}$ When the countercyclical capital buffer is zero in all of the regions to which a bank has private sector credit exposures, the capital levels and restrictions set out in the table are the same as those set out in section III.

51 The Committee is still reviewing the question of permitting other fully loss absorbing capital beyond Common Equity Tier 1 and what form it would take. Until the Committee has issued further guidance, the countercyclical buffer is to be met with Common Equity Tier 1 only.

52 When considering the jurisdiction to which a private sector credit exposure relates, banks should use, where possible, an ultimate risk basis; i.e. it should use the country where the guarantor of the exposure resides, not where the exposure has been booked.

53 Consistent with the conservation buffer, the Common Equity Tier 1 ratio in this context includes amounts used to meet the $4.5 \%$ minimum Common Equity Tier 1 requirement, but excludes any additional Common Equity Tier 1 needed to meet the $6 \%$ Tier 1 and $8 \%$ Total Capital requirements. 


\begin{tabular}{c|c}
\hline \multicolumn{2}{c}{ Individual bank minimum capital conservation standards } \\
\hline $\begin{array}{c}\text { Common Equity Tier 1 (including other } \\
\text { fully loss absorbing capital) }\end{array}$ & $\begin{array}{c}\text { Minimum Capital Conservation Ratios } \\
\text { (expressed as a percentage of earnings) }\end{array}$ \\
\hline Within first quartile of buffer & $100 \%$ \\
\hline Within second quartile of buffer & $80 \%$ \\
\hline Within Third quartile of buffer & $60 \%$ \\
\hline Within Fourth quartile of buffer & $40 \%$ \\
\hline Above top of buffer & $0 \%$
\end{tabular}

148. For illustrative purposes, the following table sets out the conservation ratios a bank must meet at various levels of Common Equity Tier 1 capital if the bank is subject to a $2.5 \%$ countercyclical buffer requirement.

\begin{tabular}{|c|c|}
\hline \multicolumn{2}{|c|}{$\begin{array}{l}\text { Individual bank minimum capital conservation standards, when a } \\
\text { bank is subject to a } 2.5 \% \text { countercyclical requirement }\end{array}$} \\
\hline $\begin{array}{c}\text { Common Equity Tier } 1 \text { Ratio } \\
\text { (including other fully loss absorbing } \\
\text { capital) }\end{array}$ & $\begin{array}{l}\text { Minimum Capital Conservation Ratios } \\
\text { (expressed as a percentage of earnings) }\end{array}$ \\
\hline $4.5 \%-5.75 \%$ & $100 \%$ \\
\hline$>5.75 \%-7.0 \%$ & $80 \%$ \\
\hline$>7.0 \%-8.25 \%$ & $60 \%$ \\
\hline$>8.25 \%-9.5 \%$ & $40 \%$ \\
\hline$>9.5 \%$ & $0 \%$ \\
\hline
\end{tabular}

\section{E. Frequency of calculation and disclosure}

149. Banks must ensure that their countercyclical buffer requirements are calculated and publically disclosed with at least the same frequency as their minimum capital requirements. The buffer should be based on the latest relevant jurisdictional countercyclical buffers that are available at the date that they calculate their minimum capital requirement. In addition, when disclosing their buffer requirement, banks must also disclose the geographic breakdown of their private sector credit exposures used in the calculation of the buffer requirement.

\section{F. Transitional arrangements}

150. The countercyclical buffer regime will be phased-in in parallel with the capital conservation buffer between 1 January 2016 and year end 2018 becoming fully effective on 1 January 2019. This means that the maximum countercyclical buffer requirement will begin at $0.625 \%$ of RWAs on 1 January 2016 and increase each subsequent year by an additional 0.625 percentage points, to reach its final maximum of $2.5 \%$ of RWAs on 1 January 2019. Countries that experience excessive credit growth during this transition period will consider accelerating the build up of the capital conservation buffer and the countercyclical buffer. In addition, jurisdictions may choose to implement larger countercyclical buffer requirements. In such cases the reciprocity provisions of the regime will not apply to the additional amounts or earlier time-frames. 


\section{Leverage ratio}

\section{A. Rationale and objective}

151. One of the underlying features of the crisis was the build-up of excessive on- and off-balance sheet leverage in the banking system. In many cases, banks built up excessive leverage while still showing strong risk based capital ratios. During the most severe part of the crisis, the banking sector was forced by the market to reduce its leverage in a manner that amplified downward pressure on asset prices, further exacerbating the positive feedback loop between losses, declines in bank capital, and contraction in credit availability.

152. Therefore, the Committee agreed to introduce a simple, transparent, non-risk based leverage ratio that is calibrated to act as a credible supplementary measure to the risk based capital requirements. The leverage ratio is intended to achieve the following objectives:

- $\quad$ constrain the build-up of leverage in the banking sector, helping avoid destabilising deleveraging processes which can damage the broader financial system and the economy; and

- $\quad$ reinforce the risk based requirements with a simple, non-risk based "backstop" measure.

\section{B. Definition and calculation of the leverage ratio}

153. This section presents the definition and calculation of the leverage ratio, which would serve as the basis for testing during the parallel run period. The basis of calculation is the average of the monthly leverage ratio over the quarter based on the definitions of capital (the capital measure) and total exposure (the exposure measure) specified in paragraphs 154 to 164 . The Committee will test a minimum Tier 1 leverage ratio of $3 \%$ during the parallel run period from 1 January 2013 to 1 January 2017. Additional transitional arrangements are set out in paragraphs 165 to 167.

\section{Capital measure}

154. The capital measure for the leverage ratio should be based on the new definition of Tier 1 capital as set out in paragraphs 52 to 56 of this Framework. The Committee also will collect data during the transition period to track the impact of using total regulatory capital and Common Equity Tier 1.

155. Items that are deducted completely from capital do not contribute to leverage, and should therefore also be deducted from the measure of exposure. That is, the capital and exposure should be measured consistently and should avoid double counting. This means that deductions from Tier 1 capital (as set out in paragraphs 66 to 89) should also be made from the exposure measure.

156. According to the treatment outlined in paragraphs 84 to 89 , where a financial entity is included in the accounting consolidation but not in the regulatory consolidation, the investments in the capital of these entities are required to be deducted to the extent that that they exceed certain thresholds. To ensure that the capital and exposure are measured consistently for the purposes of the leverage ratio, the assets of such entities included in the accounting consolidation should be excluded from the exposure measure in proportion to the capital that is excluded under paragraphs 84 to 89 . 


\section{Exposure measure}

(i) General measurement principles

157. The exposure measure for the leverage ratio should generally follow the accounting measure of exposure. To be measured consistently with financial accounts, the following should apply:

- $\quad$ on-balance sheet, non-derivative exposures are net of specific provisions and valuation adjustments (eg credit valuation adjustments);

- $\quad$ physical or financial collateral, guarantees or credit risk mitigation purchased is not allowed to reduce on-balance sheet exposures; and

- $\quad$ netting of loans and deposits is not allowed.

\section{(ii) On-balance sheet items}

158. Banks should include items using their accounting balance sheet for the purposes of the leverage ratio. In addition, the exposure measure should include the following treatments for Securities Financing Transactions $(\mathrm{SFT})^{54}$ and derivatives.

\section{(a) Repurchase agreements and securities finance}

159. SFT are a form of secured funding and therefore an important source of balance sheet leverage that should be included in the leverage ratio. Therefore, banks should calculate SFT for the purposes of the leverage ratio by applying:

- $\quad$ the accounting measure of exposure; and

- $\quad$ the regulatory netting rules based on the Basel II Framework. ${ }^{55}$

(b) Derivatives

160. Derivatives create two types of exposure: an "on-balance sheet" present value reflecting the fair value of the contract (often zero at outset but subsequently positive or negative depending on the performance of the contract), and a notional economic exposure representing the underlying economic interest of the contract.

161. Banks should calculate derivatives, including where a bank sells protection using a credit derivative, for the purposes of the leverage ratio by applying:

- $\quad$ the accounting measure of exposure plus an add-on for potential future exposure calculated according to the Current Exposure Method as identified in paragraphs 186, 187 and 317 of the Basel II Framework. This ensures that all derivatives are converted in a consistent manner to a "Ioan equivalent" amount; and

- $\quad$ the regulatory netting rules based on the Basel II Framework. ${ }^{56}$

\footnotetext{
4 Securities Financing Transactions are transactions such as repurchase agreements, reverse repurchase agreements, security lending and borrowing, and margin lending transactions, where the value of the transactions depends on the market valuations and the transactions are often subject to margin agreements.

Excepting the rules for cross-product netting in Annex 4, section 3.

56 Excepting the rules for cross-product netting in Annex 4, section 3.
} 
(iii) Off-balance sheet items

162. This section relates to off-balance sheet (OBS) items in paragraphs 82-83, (including 83(i)), 84(i-iii), 85-86, and 88-89) of the Basel II Framework. These include commitments (including liquidity facilities), unconditionally cancellable commitments, direct credit substitutes, acceptances, standby letters of credit, trade letters of credit, failed transactions and unsettled securities. The treatment of the items included in 83(ii) and 84, ie repurchase agreements and securities financing transactions is addressed above.

163. The Committee recognises that OBS items are a source of potentially significant leverage. Therefore, banks should calculate the above OBS items for the purposes of the leverage ratio by applying a uniform $100 \%$ credit conversion factor (CCF).

164. For any commitments that are unconditionally cancellable at any time by the bank without prior notice, banks should apply a CCF of $10 \%$. The Committee will conduct further review to ensure that the $10 \%$ CCF is appropriately conservative based on historical experience.

\section{Transitional arrangements}

165. The transition period for the leverage ratio will commence 1 January 2011. The Committee will use the transition period to monitor banks' leverage data on a semi-annual basis in order to assess whether the proposed design and calibration of the minimum Tier 1 leverage ratio of $3 \%$ is appropriate over a full credit cycle and for different types of business models. This assessment will include consideration of whether a wider definition of exposures and an offsetting adjustment in the calibration would better achieve the objectives of the leverage ratio. The Committee also will closely monitor accounting standards and practices to address any differences in national accounting frameworks that are material to the definition and calculation of the leverage ratio.

166. The transition period will comprise of a supervisory monitoring period and a parallel run period:

- $\quad$ The supervisory monitoring period commences 1 January 2011. The supervisory monitoring process will focus on developing templates to track in a consistent manner the underlying components of the agreed definition and resulting ratio.

- $\quad$ The parallel run period commences 1 January 2013 and runs until 1 January 2017. During this period, the leverage ratio and its components will be tracked, including its behaviour relative to the risk based requirement. Banks are required to calculate their leverage ratio using the definitions of capital and total exposure specified in paragraphs 154 to 164 and their risk based capital requirement. Bank level disclosure of the leverage ratio and its components will start 1 January $2015{ }^{57}$ The Committee will develop a disclosure template and closely monitor disclosure of the ratio.

167. Based on the results of the parallel run period, any final adjustments to the definition and calibration of the leverage ratio will be carried out in the first half of 2017 , with a view to migrating to a Pillar 1 treatment on 1 January 2018 based on appropriate review and calibration.

57 Consistent with the scope of application as defined in paragraph 22 of the Basel II Framework. 


\section{Annex 1}

\section{Calibration of the capital framework}

\section{Calibration of the Capital Framework}

Capital requirements and buffers (all numbers in percent)

\begin{tabular}{l|c|c|c}
\hline & $\begin{array}{c}\text { Common Equity } \\
\text { Tier 1 }\end{array}$ & Tier 1 Capital & Total Capital \\
\hline Minimum & 4.5 & 6.0 & 8.0 \\
\hline
\end{tabular}

\begin{tabular}{l|c|}
\hline Conservation buffer & 2.5 \\
\hline
\end{tabular}

\begin{tabular}{l|c|c|c}
\hline $\begin{array}{l}\text { Minimum plus } \\
\text { conservation buffer }\end{array}$ & 7.0 & 8.5 & 10.5 \\
\hline
\end{tabular}

\begin{tabular}{l|c|}
\hline $\begin{array}{l}\text { Countercyclical buffer } \\
\text { range }^{*}\end{array}$ & $0-2.5$ \\
\hline
\end{tabular}

* See footnote 53 


\section{Annex 2}

\section{The $15 \%$ of common equity limit on specified items}

1. This Annex is meant to clarify the calculation of the $15 \%$ limit on significant investments in the common shares of unconsolidated financial institutions (banks, insurance and other financial entities); mortgage servicing rights, and deferred tax assets arising from temporary differences (collectively referred to as specified items).

2. The recognition of these specified items will be limited to $15 \%$ of Common Equity Tier 1 (CET1) capital, after the application of all deductions. To determine the maximum amount of the specified items that can be recognised*, banks and supervisors should multiply the amount of $\mathrm{CET} 1^{* *}$ (after all deductions, including after the deduction of the specified items in full) by $17.65 \%$. This number is derived from the proportion of $15 \%$ to $85 \%$ (ie $15 \% / 85 \%=17.65 \%$ ).

3. As an example, take a bank with $€ 85$ of common equity (calculated net of all deductions, including after the deduction of the specified items in full).

4. The maximum amount of specified items that can be recognised by this bank in its calculation of CET1 capital is $€ 85 \times 17.65 \%=€ 15$. Any excess above $€ 15$ must be deducted from CET1. If the bank has specified items (excluding amounts deducted after applying the individual $10 \%$ limits) that in aggregate sum up to the $15 \%$ limit, CET1 after inclusion of the specified items, will amount to $€ 85+€ 15=€ 100$. The percentage of specified items to total CET1 would equal $15 \%$.

* The actual amount that will be recognised may be lower than this maximum, either because the sum of the three specified items are below the $15 \%$ limit set out in this annex, or due to the application of the $10 \%$ limit applied to each item.

** At this point this is a "hypothetical" amount of CET1 in that it is used only for the purposes of determining the deduction of the specified items. 


\section{Annex 3}

\section{Minority interest illustrative example}

This Annex illustrates the treatment of minority interest and other capital issued out of subsidiaries to third parties, which is set out in paragraphs 62 to 64 .

\section{Illustrative example}

A banking group consists of two legal entities that are both banks. Bank $P$ is the parent and Bank $S$ is the subsidiary and their unconsolidated balance sheets are set out below.

\begin{tabular}{l|r|l|r}
\hline \multicolumn{1}{c|}{ Bank P balance sheet } & \multicolumn{1}{|c}{ Bank S balance sheet } & \\
\hline Assets & 100 & Assets & Loans to customers \\
Loans to customers & 7 & & 150 \\
Investment in CET1 of Bank S & 4 & & \\
Investment in the AT1 of Bank S & 2 & & \\
Investment in the T2 of Bank S & & Liabilities and equity & \\
Liabilities and equity & 70 & Depositors & 127 \\
Depositors & 10 & Tier 2 & 8 \\
Tier 2 & 7 & Additional Tier 1 & 5 \\
Additional Tier 1 & 26 & Common equity & 10 \\
Common equity &
\end{tabular}

The balance sheet of Bank $\mathrm{P}$ shows that in addition to its loans to customers, it owns $70 \%$ of the common shares of Bank S, $80 \%$ of the Additional Tier 1 of Bank S and $25 \%$ of the Tier 2 capital of Bank S. The ownership of the capital of Bank $S$ is therefore as follows:

Capital issued by Bank S

\begin{tabular}{l|c|c|c}
\hline & $\begin{array}{c}\text { Amount issued } \\
\text { to parent } \\
\text { (Bank P) }\end{array}$ & $\begin{array}{c}\text { Amount issued } \\
\text { to third parties }\end{array}$ & Total \\
\hline Common Equity Tier 1 (CET1) & 7 & 3 & 10 \\
\hline Additional Tier 1 (AT1) & 4 & 1 & 5 \\
\hline Tier 1 (T1) & $\mathbf{1 1}$ & $\mathbf{4}$ & $\mathbf{1 5}$ \\
\hline Tier 2 (T2) & 2 & 6 & 8 \\
\hline Total capital (TC) & $\mathbf{1 3}$ & $\mathbf{1 0}$ & $\mathbf{2 3}$ \\
\hline
\end{tabular}

The consolidated balance sheet of the banking group is set out below: 


\section{Consolidated balance sheet}

\section{Assets}

Loans to customers

Liabilities and equity

Depositors

Tier 2 issued by subsidiary to third parties

Tier 2 issued by parent

Additional Tier 1 issued by subsidiary to third parties

Additional Tier 1 issued by parent

Common equity issued by subsidiary to third parties (ie minority interest)

Common equity issued by parent

For illustrative purposes Bank $S$ is assumed to have risk weighted assets of 100 . In this example, the minimum capital requirements of Bank $S$ and the subsidiary's contribution to the consolidated requirements are the same since Bank $S$ does not have any loans to Bank $P$. This means that it is subject to the following minimum plus capital conservation buffer requirements and has the following surplus capital:

Minimum and surplus capital of Bank S

\begin{tabular}{l|c|c}
\hline & $\begin{array}{c}\text { Minimum plus capital } \\
\text { conservation buffer }\end{array}$ & Surplus \\
\hline CET1 & 7.0 & 3.0 \\
$(=7.0 \%$ of 100$)$ & $(=10-7.0)$ \\
\hline T1 & 8.5 & 6.5 \\
& $(=8.5 \%$ of 100$)$ & $(=10+5-8.5)$ \\
\hline TC & 10.5 & 12.5 \\
& $(=10.5 \%$ of 100$)$ & $(=10+5+8-10.5)$ \\
\hline
\end{tabular}

The following table illustrates how to calculate the amount of capital issued by Bank $S$ to include in consolidated capital, following the calculation procedure set out in paragraphs 62 to 65 :

Bank S: amount of capital issued to third parties included in consolidated capital

\begin{tabular}{c|c|c|c|c|c}
\hline & $\begin{array}{c}\text { Total amount } \\
\text { issued } \\
\text { (a) }\end{array}$ & $\begin{array}{c}\text { Amount } \\
\text { issued to third } \\
\text { parties } \\
\text { (b) }\end{array}$ & $\begin{array}{c}\text { Surplus } \\
\text { (c) }\end{array}$ & $\begin{array}{c}\text { Surplus } \\
\text { attributable to } \\
\text { third parties } \\
\text { (ie amount } \\
\text { excluded from } \\
\text { consolidated } \\
\text { capital) } \\
\text { (d) } \\
\text { (c) * (b)/(a) }\end{array}$ & $\begin{array}{c}\text { Amount } \\
\text { included in } \\
\text { consolidated } \\
\text { capital } \\
\text { (e) = (b) - (d) }\end{array}$ \\
\hline CET1 & 10 & 3 & 3.0 & 0.90 & 2.10 \\
\hline T1 & 15 & 4 & 6.5 & 1.73 & 2.27 \\
\hline TC & 23 & 10 & 12.5 & 5.43 & 4.57 \\
\hline
\end{tabular}


The following table summarises the components of capital for the consolidated group based on the amounts calculated in the table above. Additional Tier 1 is calculated as the difference between Common Equity Tier 1 and Tier 1 and Tier 2 is the difference between Total Capital and Tier 1.

\begin{tabular}{l|c|c|c}
\hline & $\begin{array}{c}\text { Total amount issued by } \\
\text { parent (all of which is to } \\
\text { be included in } \\
\text { consolidated capital) }\end{array}$ & $\begin{array}{c}\text { Amount issued by } \\
\text { subsidiaries to third } \\
\text { parties to be included in } \\
\text { consolidated capital }\end{array}$ & $\begin{array}{c}\text { Total amount issued by } \\
\text { parent and subsidiary to } \\
\text { be included in } \\
\text { consolidated capital }\end{array}$ \\
\hline CET1 & 26 & 2.10 & 28.10 \\
\hline AT1 & 7 & 0.17 & 7.17 \\
\hline T1 & 33 & 2.27 & 35.27 \\
\hline T2 & 10 & 2.30 & 12.30 \\
\hline TC & 43 & 4.57 & 47.57 \\
\hline
\end{tabular}




\section{Annex 4}

\section{Phase-in arrangements}

(shading indicates transition periods - all dates are as of 1 January)

\begin{tabular}{|c|c|c|c|c|c|c|c|c|c|}
\hline & 2011 & 2012 & 2013 & 2014 & 2015 & 2016 & 2017 & 2018 & $\begin{array}{l}\text { As of } \\
1 \text { January } \\
2019\end{array}$ \\
\hline Leverage Ratio & \multicolumn{2}{|c|}{ Supervisory monitoring } & \multicolumn{4}{|c|}{$\begin{array}{c}\text { Parallel run } \\
1 \text { Jan } 2013-1 \text { Jan } 2017 \\
\text { Disclosure starts } 1 \text { Jan } 2015\end{array}$} & & $\begin{array}{l}\text { Migration to } \\
\text { Pillar } 1\end{array}$ & \\
\hline Minimum Common Equity Capital Ratio & & & $3.5 \%$ & $4.0 \%$ & $4.5 \%$ & $4.5 \%$ & $4.5 \%$ & $4.5 \%$ & $4.5 \%$ \\
\hline Capital Conservation Buffer & & & & & & $0.625 \%$ & $1.25 \%$ & $1.875 \%$ & $2.50 \%$ \\
\hline $\begin{array}{l}\text { Minimum common equity plus capital } \\
\text { conservation buffer }\end{array}$ & & & $3.5 \%$ & $4.0 \%$ & $4.5 \%$ & $5.125 \%$ & $5.75 \%$ & $6.375 \%$ & $7.0 \%$ \\
\hline $\begin{array}{l}\text { Phase-in of deductions from CET1 } \\
\text { (including amounts exceeding the limit for } \\
\text { DTAs, MSRs and financials ) }\end{array}$ & & & & $20 \%$ & $40 \%$ & $60 \%$ & $80 \%$ & $100 \%$ & $100 \%$ \\
\hline Minimum Tier 1 Capital & & & $4.5 \%$ & $5.5 \%$ & $6.0 \%$ & $6.0 \%$ & $6.0 \%$ & $6.0 \%$ & $6.0 \%$ \\
\hline Minimum Total Capital & & & $8.0 \%$ & $8.0 \%$ & $8.0 \%$ & $8.0 \%$ & $8.0 \%$ & $8.0 \%$ & $8.0 \%$ \\
\hline $\begin{array}{l}\text { Minimum Total Capital plus conservation } \\
\text { buffer }\end{array}$ & & & $8.0 \%$ & $8.0 \%$ & $8.0 \%$ & $8.625 \%$ & $9.25 \%$ & $9.875 \%$ & $10.5 \%$ \\
\hline $\begin{array}{l}\text { Capital instruments that no longer qualify } \\
\text { as non-core Tier } 1 \text { capital or Tier } 2 \text { capital }\end{array}$ & & & \multicolumn{7}{|c|}{ Phased out over 10 year horizon beginning 2013} \\
\hline Liquidity coverage ratio & $\begin{array}{l}\text { Observation } \\
\text { period } \\
\text { begins }\end{array}$ & & & & $\begin{array}{l}\text { Introduce } \\
\text { minimum } \\
\text { standard }\end{array}$ & & & & \\
\hline Net stable funding ratio & $\begin{array}{l}\text { Observation } \\
\text { period } \\
\text { begins }\end{array}$ & & & & & & & $\begin{array}{l}\text { Introduce } \\
\text { minimum } \\
\text { standard }\end{array}$ & \\
\hline
\end{tabular}

